Aus der Klinik Hals-Nasen-Ohrenheilkunde

(Prof. Dr. med. D. Beutner)

der Medizinischen Fakultät der Universität Göttingen

\title{
Medikamentöse Defibrinogenierung zur Behandlung des akuten Hörverlustes - eine verblindete, placebokontrollierte In-vivo-Studie
}

\author{
INAUGURAL-DISSERTATION \\ zur Erlangung des Doktorgrades \\ für Zahnmedizin \\ der Medizinischen Fakultät der \\ Georg-August-Universität zu Göttingen
}

vorgelegt von

Stephan Alexander Bettag

aus

Essen

Göttingen 2020 
Dekan:

Referent/in:

Ko-Referent/in:

Drittreferent/in:
Prof. Dr. med. W. Brück

Prof. Dr. Martin Canis

Prof. Dr. Michael Koziolek

Prof. Dr. Rainer Mausberg

Datum der mündlichen Prüfung: 30.11.2020 
Hiermit erkläre ich, die Dissertation mit dem Titel "Medikamentöse Defibrinogenierung zur Behandlung des akuten Hörverlustes - eine verblindete, placebokontrollierte In-vivo-Studie" eigenständig angefertigt und keine anderen als die von mir angegebenen Quellen und Hilfsmittel verwendet zu haben.

Göttingen, den ................ 
Die Daten, auf denen die vorliegende Arbeit basiert, wurden teilweise publiziert:

Weiss BG, Bertlich M, Bettag SA, Desinger H, Ihler F, Canis, M (2017): Drug-induced defibrinogenation as new treatment approach of acute hearing loss in an animal model for inner ear vascular impairment. Otol Neurotol 2017 Jun;38(5): 648-654 


\section{Inhaltsverzeichnis}

Abkürzungsverzeichnis und Legende .................................................................................

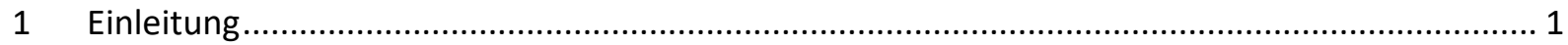

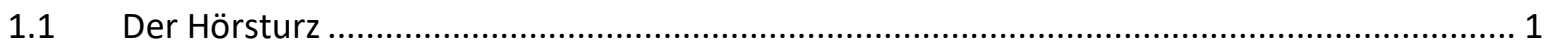

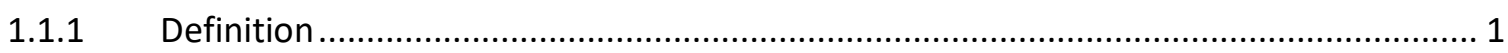

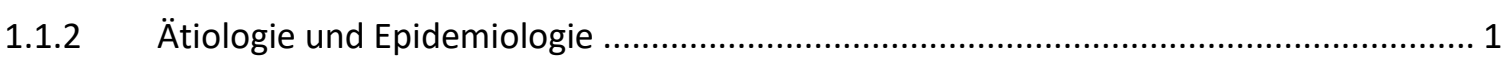

1.1.3 Symptomatik und Differentialdiagnosen ................................................................ 2

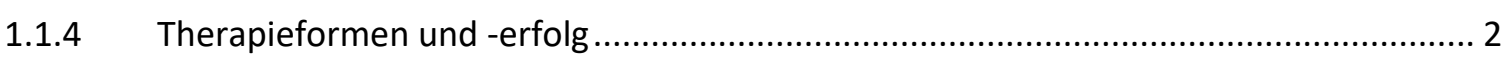

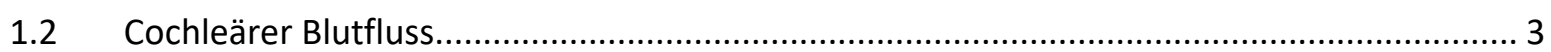

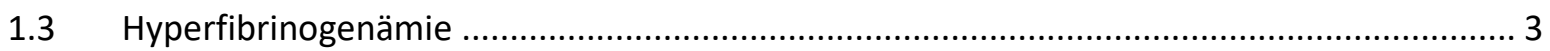

1.4 Defibrinogenierung als Therapieansatz für einen idiopathischen Hörsturz............................ 4

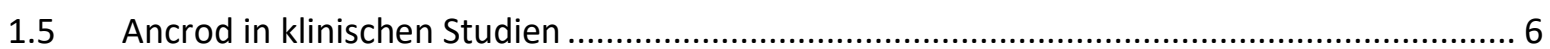

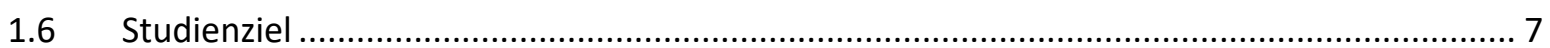

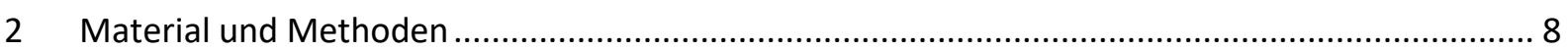

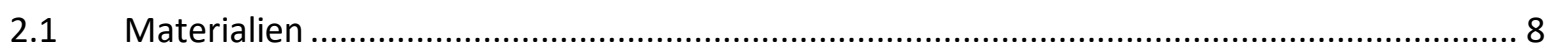

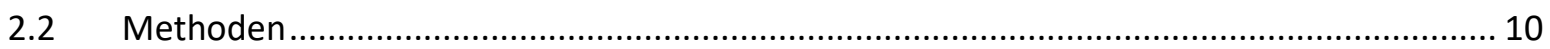

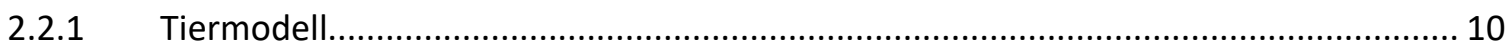

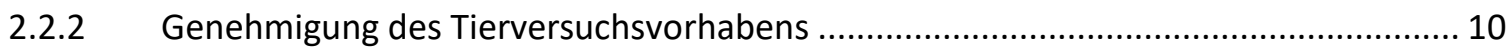

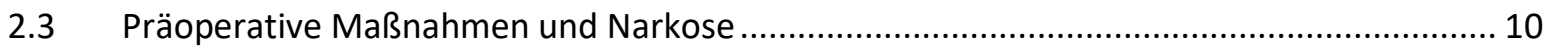

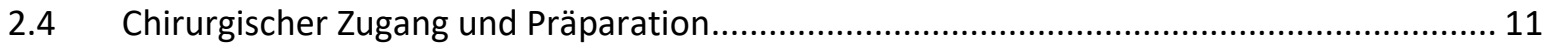

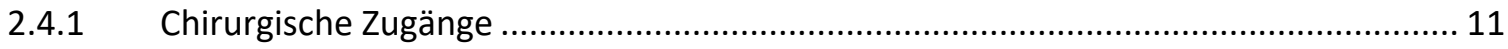

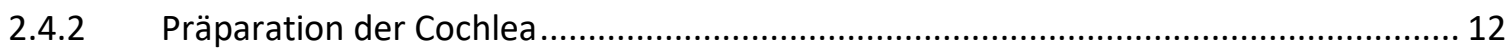

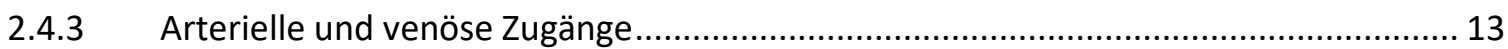

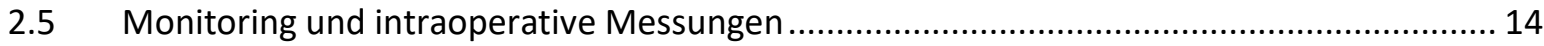

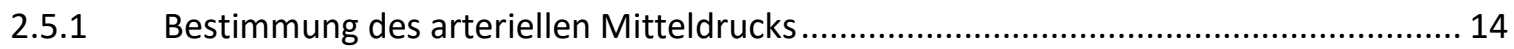

2.5.2 Bestimmung der Hörschwelle mittels Hirnstammaudiometrie (BERA) ....................... 15

2.5.3 Bestimmung der Fibrinogenkonzentration ............................................................... 16

2.5.4 Bestimmung des cochleären Blutflusses .................................................................... 17

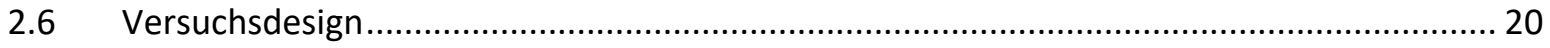

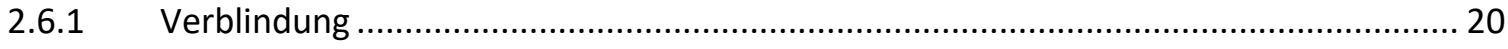

2.6.2 Bestimmung der Basisparameter ......................................................................... 20

2.6.3 Induzieren eines plötzlichen Hörverlusts durch Hyperfibrinogenämie.......................... 20

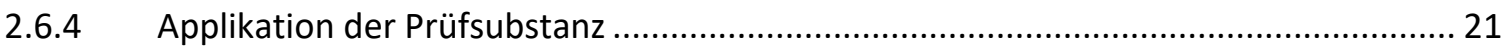




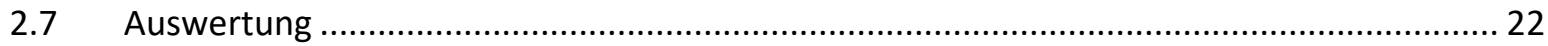

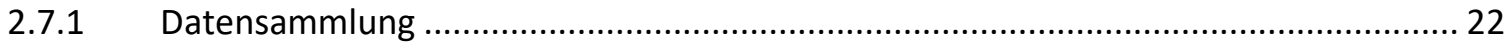

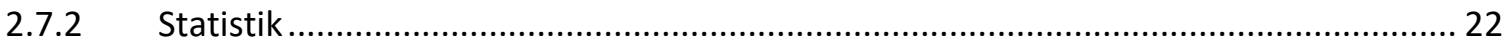

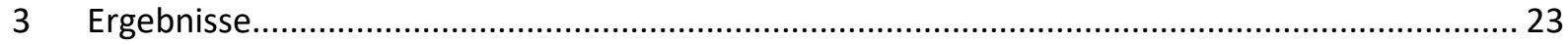

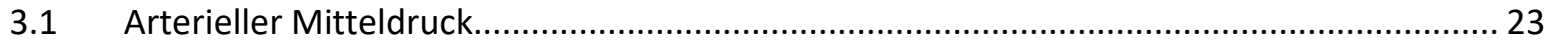

3.2 Veränderung der Messparameter nach Fibrinogeninjektion in der Placebo-Gruppe .......... 24

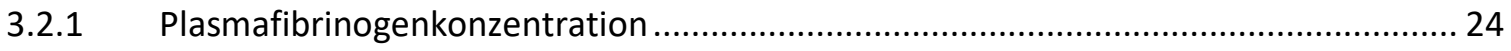

3.2.2 Hörschwelle (Hirnstammaudiometrie) ..................................................................... 25

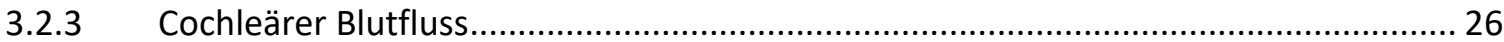

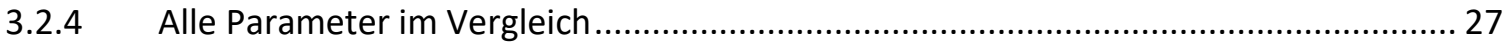

3.3 Verbesserung des akuten, durch Hyperfibrinogenämie induzierten Hörverlusts unter

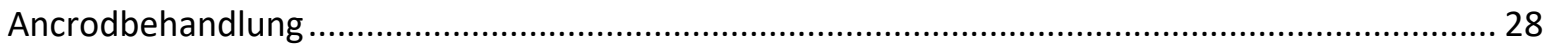

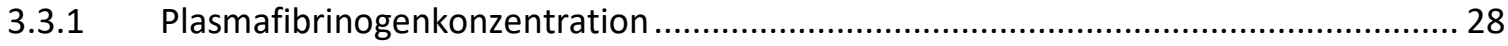

3.3.2 Hörschwelle (Hirnstammaudiometrie) .............................................................................. 30

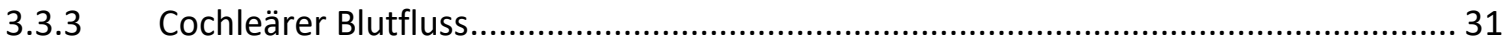

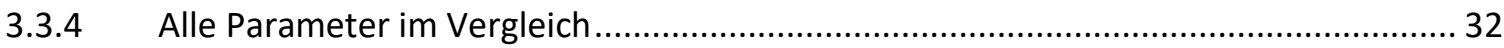

3.4 Statistischer Gruppenvergleich (Placebo vs. Ancrod) …..................................................... 33

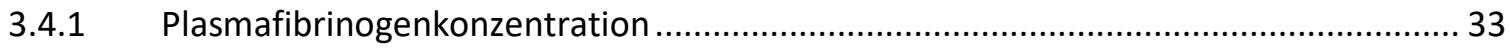

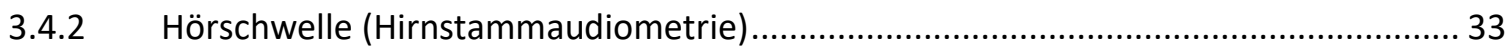

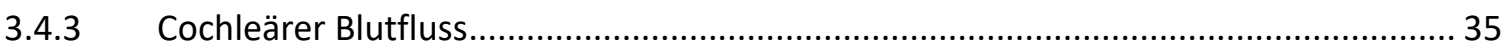

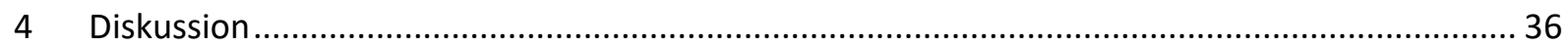

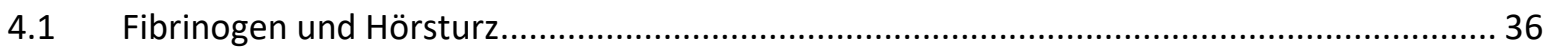

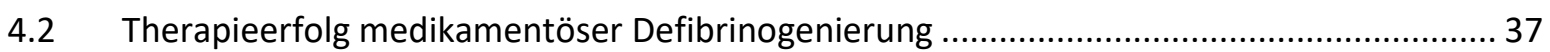

4.3 Medikamentöse Defibrinogenierung als Therapiealternative zum therapeutischen Standard 39

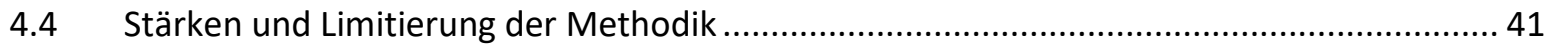

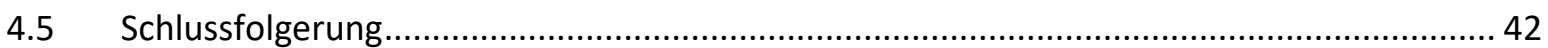

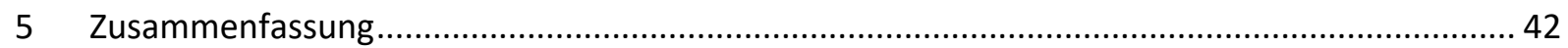

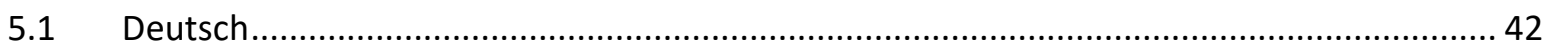

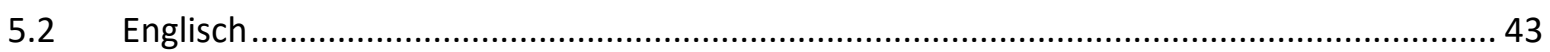

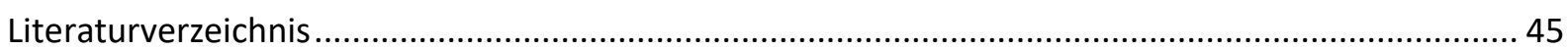

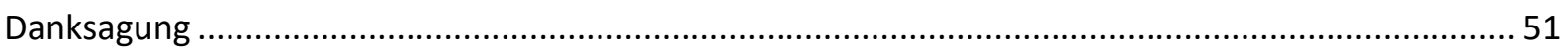

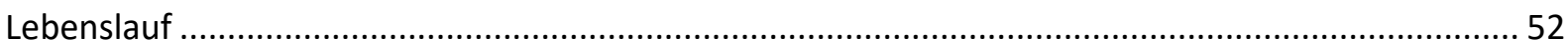




\section{Abkürzungsverzeichnis und Legende}

AICA

BERA

CBF

EA

FITC

HS

IVM

KG

NIDCD

NPGB

PFK

SVTLE

U

ZVK

$*$

** anterior inferior cerebellar artery (A. cerebelli anterior inferior)

brainstem evoked response audiometry (Hirnstamm-Audiometrie)

cochlear blood flow (cochleärer Blutfluss)

Erythrozytenaggregation

Flouresceinisothiocyanat-Dextran $(150.000 \mathrm{~mol} \mathrm{wt})$

Hörschwelle

Intravitalmikroskopie

Körpergewicht

US National Institute for Deafness and Communication Disorders

Nitrophenol-P-Guanidin-Benzoat-Hydrochlorid

Plasmafibrinogenkonzentration

snake venom thrombin-like enzyme

ancrod units

Zentralvenöser Katheter

Signifikante Veränderung $(p<0,05)$

Signifikante Veränderung $(p<0,01)$ 


\section{Einleitung}

\subsection{Der Hörsturz}

\subsubsection{Definition}

Das plötzliche, einseitige Auftreten einer Schallempfindungsschwerhörigkeit, allgemein als Hörsturz bekannt, ist eine häufige Erkrankung des Innenohrs. Die am häufigsten gebräuchliche Definition wurde vom US National Institute for Deafness and Communication Disorders (NIDCD) festgelegt und beschreibt die Krankheit als einen plötzlichen Hörverlust von mindestens $30 \mathrm{~dB}$ bei drei aufeinander folgenden audiometrischen Frequenzen über eine Zeit von mindestens 72 Stunden (Kuhn et al. 2011; Weber et al. 2013).

\subsection{2 Ätiologie und Epidemiologie}

Die Ätiologie ist weitgehend ungeklärt, in den meisten Fällen kann keine Ursache für den Hörsturz identifiziert werden, man bezeichnet diesen dann als idiopathischen Hörsturz (Foden et al. 2013). Zu einem deutlich geringeren Anteil sind die Gründe für die Entstehung eines plötzlichen Hörverlusts bekannt und werden Infektionskrankheiten (13\%), Erkrankungen des Innenohres, wie beispielsweise dem Morbus Menière, einer Otosklerose oder Autoimmunerkrankungen (5 \%), Trauma (4 \%), vaskulären oder hämatologischen Ursachen (3 \%), Neoplasien (2 \%), Kohlenstoffmonoxid-Vergiftungen, Impfungen oder einer Schwangerschaft (2 \%) zugeordnet (Chau et al. 2010). Bei den pathomechanisch zugrundeliegenden Hypothesen spielt die vaskulär/hämatologisch bedingte Schallempfindungsschwerhörigkeit eine herausragende Rolle (Chau et al. 2010).

Die Inzidenz ist nicht einheitlich angegeben, da es bei vielen erkrankten Patienten zu einer raschen Spontanheilung der Schallempfindungsschwerhörigkeit kommt, bevor diese als Erkrankte erfasst werden (Kuhn et al. 2011). Die beschriebenen Inzidenzen liegen zwischen 5 und 200 pro 100.000 Einwohner pro Jahr (Olzowy et al. 2005; Kuhn et al. 2011; Weber et al. 
2013). Die Krankheit tritt am häufigsten zwischen der fünften und sechsten Lebensdekade, bei Männern und Frauen vergleichbar häufig und in 98 \% der Fälle unilateral auf (Kuhn et al. 2011).

\subsubsection{Symptomatik und Differentialdiagnosen}

Die Patienten erkranken plötzlich und das Leitsymptom ist der spürbar meist unilaterale Hörverlust. In bis zu 90 \% der Fälle geht dies mit einem Tinnitus einher. 20-60\% der Patienten mit Hörsturz klagen zudem über Schwindel, gelegentlich kommt es auch zu Otalgie oder Parästhesien.

Diagnostisch müssen durch eine Otoskopie die Otitis media oder Otitis externa, ebenso wie Verlegung des Gehörgangs durch Fremdkörper oder Cerumen, eine Perforation des Trommelfells oder ein Cholesteatom ausgeschlossen werden. Eine Untersuchung mittels Magnetresonanztomographie kann Hinweise auf weitere Krankheiten mit ähnlicher Symptomatik geben, beispielsweise Akustikusneurinome, zerebrovaskuläre Insuffizienz, Morbus Menière oder Multiple Sklerose. Diese Untersuchung ist in der Primärdiagnostik jedoch noch nicht angezeigt.

Da viele mit einer Hörminderung einhergehende Krankheiten aufgrund der meist bilateral auftretenden Schwerhörigkeit gegenüber dem Hörsturz abgegrenzt werden können, bleibt als Differentialdiagnose in erster Linie der Schlaganfall, typischerweise ausgelöst durch einen Verschluss der A. cerebelli inferior anterior (Weber et al. 2013). Dieser würde allerdings in den meisten Fällen zusätzlich andere Symptome, wie beispielsweise Diplopie, unilaterale Fazialisparese, Parästhesien, Ataxie oder Nystagmus hervorrufen.

\subsubsection{Therapieformen und -erfolg}

Die Therapie des Hörsturzes richtet sich maßgeblich nach der Ursache, die jedoch in mehr als 70 \% der Fälle ungeklärt ist (idiopathischer sensorineuraler Hörverlust). Nur in wenigen Fällen konnte bei identifizierter Ursache, wie einem Hörverlust im Rahmen eines Akustikusneurinoms, Mumpsinfektion oder sekundärer Lues, eine komplette Ausheilung der Schallempfindungsschwerhörigkeit erzielt werden (Berg et al. 1986; Jeans et al. 2008; Vuori et al. 1962). In der Regel ist auch bei identifizierter Ursache nach adäquater Behandlung beim Gros der Patienten keine Restitutio ad integrum zu erwarten (Kuhn et al. 2011). Der idiopathische Hörsturz 
hingegen scheint bei 45-65 \% der Patienten spontan auszuheilen, das Hörvermögen verbessert sich um durchschnittlich $35 \mathrm{~dB}$ unabhängig von der medikamentösen Behandlung (Mattox and Simmons 1977; Byl 1984). Dies ist Grundlage für die Frage der Notwendigkeit einer Behandlung bei idiopathischem Hörsturz. Es wurde in Metaanalysen gezeigt, dass der aktuelle therapeutische Standard, die systemische Behandlung mit Kortikosteroiden, keine bessere Wirkung aufweist als die Gabe von Placebo (Conlin und Parnes 2007; Crane et al. 2015). Weitere Therapieansätze für den Hörsturz sind die hyperbare Sauerstoff-Therapie, die Gabe von Antiphlogistika, Vitaminen, Calcium-Antagonisten, Mineralien, Vasodilatatoren und Diuretika. Ein Wirksamkeitsnachweis beschränkt sich jedoch auf nur wenige Fallbeispiele, bei denen eine Mono- oder kombinierte Therapie Erfolg versprechende Resultate liefert. Placebo-kontrollierte verblindete Studien, die einen signifikanten Wirksamkeitsnachweis einer Therapiestrategie belegen, existieren nicht (Mattox and Simmons 1977; Conlin und Parnes 2007).

\subsection{Cochleärer Blutfluss}

Durch die schlecht zugängliche Lage im Os temporale ist die Inspektion und damit verbundene Diagnostik von Erkrankungen des Innenohrs äußerst komplex. Dabei können rheologische Funktionsstörungen in der Cochlea ursächlich sein für otologische Erkrankungen, wie Hörverlust, Endolymph-Hydrops oder Presbyakusis (Nakashima et al. 2003). Die Blutversorgung der Cochlea wird gewährleistet durch die A. labyrinthi, einen Ast der A. cerebelli inferior anterior, die im weiteren Verlauf Äste abgibt, deren Arteriolen unter anderem die Stria vascularis bilden (Nakashima et al. 2003). Ist der cochleäre Blutfluss (CBF) gestört oder unterbrochen, kann es zu schweren Degenerationen des Corti-Organs, der Stria vascularis und des Ligamentum spirale kommen (Gussen 1976).

\subsection{Hyperfibrinogenämie}

Als Einflussfaktor auf die cochleäre Mikrozirkulation gilt das Plasmaprotein Fibrinogen (Suckfüll et al. 2002; Ihler et al. 2012). Fibrinogen ist ein Glykoprotein mit einer Atommasse von 340 
Kilodalton ( $\mathrm{kDa})$, das in der Leber gebildet wird und physiologisch in Konzentrationen von 200$400 \mathrm{mg} / \mathrm{dL}$ im Plasma vorliegt. Es ist verschlüsselt auf drei Genen (FGA, FGB, FGC), gebündelt auf Chromosom 4q. Das Molekül zeigt eine Vielfalt von Funktionen im Körper, darunter die Bildung eines Fibrin-Geflechts bei der Wundheilung und die Vernetzung von Thrombozyten bei der Thrombozytenaggregation. Es wird im Zuge der Gerinnungskaskade durch die Serinprotease Thrombin und den Co-Faktor Calcium zu Fibrin gespalten (Acharya und DiMichele 2008). Als Akute-Phase-Protein ist es einer der bestimmenden Faktoren für die Plasmaviskosität. Durch verstärkte Thrombozyten- sowie Erythrozytenaggregation beeinflusst Fibrinogen als eines der großen Plasmaglykoproteine direkt die Vollblut- und Plasmaviskosität und damit auch den cochleären Blutfluss (Suckfüll et al. 2002). Des Weiteren wird die Synthese von Zytokinen, wie beispielsweise TNF- $\alpha$, positiv durch Fibrinogen beeinflusst. Dies führt über eine Aktivierung der Sphingosin-Kinase 1 zu einer erhöhten Konzentration von Sphingosin-1-Phosphat, einem konstriktiv auf die Arteria spiralis modiolaris wirkenden Lipid (Jensen et al. 2007; Scherer et al. 2010; Sharaf et al. 2016). Somit wird der cochleäre Blutfluss durch die Plasmafibrinogenkonzentration entscheidend beeinflusst. Eine erhöhte Plasmafibrinogenkonzentration (PFK) ist aufgrund der Erhöhung der Blutviskosität einer der rheologischen Risikofaktoren für eine plötzlich auftretende Schallempfindungsstörung (Suckfüll et al. 2002; Chau et al. 2010). Suckfüll et al. haben bei einer Gruppe von 53 Patienten mit Hörsturz gezeigt, dass Plasmafibrinogenkonzentration, Plasmaviskosität und die Erythrozytenaggregation jeweils durchschnittlich signifikant höher waren als die Werte einer Kontrollgruppe (Suckfüll et al. 2002). Auch Mannini et al. konnten bei Patienten mit Hörsturz eine signifikant höhere Plasmaviskosität nachweisen (Mannini et al. 2005).

Auch in vivo wurde die Hyperfibrinogenämie als Einflussfaktor auf den cochleären Blutfluss beschrieben (Ihler et al. 2012). Eine erhöhte Plasmafibrinogenkonzentration führte in diesem Tiermodell zu einer signifikanten Verschlechterung sowohl des cochleären Blutflusses als auch des Hörvermögens (Ihler et al. 2012).

\subsection{Defibrinogenierung als Therapieansatz für einen idiopathischen Hörsturz}

Als Einflussfaktor auf die cochleäre Mikrozirkulation könnte die Plasmafibrinogenkonzentration als therapeutisches Ziel zur Behandlung eines Hörsturzes herangezogen werden. Mittels 
Fibrinogen/LDL-Apherese haben Canis et al. 2012 bei einem Kollektiv von 217 Hörsturz-Patienten die Plasmafibrinogenkonzentration um durchschnittlich 61,6\%, den Gehalt an Triglyceriden um 56,1 \%, LDL-Cholesterin um 56,4 \% und Lipoprotein A um 62,1 \% reduziert. Das Kollektiv bestand aus erfolglos mittels hochdosierten Kortikosteroiden oder Plasmaexpandern primär therapierten Patienten. Im Rahmen der Sekundärtherapie mittels Apherese wurde einer Besserung der Hörschwelle um 14,9 dB im Mittel über alle Frequenzen beobachtet (Canis et al. 2012).

Neben der apparativen Senkung der Plasmafibrinogenkonzentration mittels Apherese ist auch eine medikamentöse bzw. enzymatische Senkung denkbar. Eine Reduktion der PFK ist durch systemische Gabe von snake venom thrombin-like enzymes (SVTLE's) möglich. Diese Serinendopeptidasen werden aus den Schlangengiften verschiedener Spezies gewonnen und sind charakterisiert durch eine fibrinogenolytische Wirkung. Bekannt sind Substanzen wie Batroxobin, Cerastocytin, Thrombocytin, Ancrod (ehemals Arvin) und viele weitere (Mackessy 2011). Batroxobin führte im Tiermodell zu einer Reduktion der Plasmafibrinogenkonzentration mit konsekutivem Anstieg des cochleären Blutflusses (Kawakami et al. 1992) und wurde in einer klinischen Studie zur Therapie des Hörsturzes eingesetzt (Shiraishi et al. 1991).

Ancrod ist ein Bestandteil des Giftes der malaiischen Mokassinotter (Calloselasma rhodostoma) und dem Batroxobin im Molekülaufbau ähnlich (Au et al. 1993). Die Wirkung dieses Enzyms ist vergleichbar der des Thrombin, einem physiologisch vorkommenden Enzym der humanen Gerinnungskaskade. Thrombin spaltet 4 der insgesamt 6 in Fibrinogen enthaltenen Fibrinopeptide ab: A, AY, AP und B (Blombäck et al. 1966). Diese modifizierten FibrinogenBestandteile bilden Fibrinmonomere und polymerisieren unter Einfluss von Gerinnungsfaktor XIII, dem Fibrinstabilisierenden Faktor oder Laki-Lorand-Faktor, zu einem Fibrin-Gel (Dempfle et al. 2001). Im Gegensatz hierzu spaltet das Enzym Ancrod nur drei Fibrinopeptide: A, AY und AP. Faktor XIII wird nicht aktiviert, da Ancrod keine proteolytische Eigenschaft gegenüber dem Fibrinstabilisierenden Faktor XIII besitzt. Es findet keine Konformationsänderung von Thrombin statt, was wiederum Faktor XIII inaktiv belässt (Dempfle et al. 2001). Durch die Ancrodinduzierte Abspaltung von Fibrinopeptid A wird auch ein Fibrin-Gel gebildet, das aus nichtquervernetztem Fibrin besteht, daher leicht abbaubar und feinstverteilt ist und zudem andere mechanische Eigenschaften als das Thrombin-induzierte Gel aufweist (Ewart et al. 1970; Prentice et al. 1993). 


\subsection{Ancrod in klinischen Studien}

Ancrod wurde bereits in klinischen Studien zur Behandlung diverser ischämischer Krankheiten, wie beispielsweise dem Apoplex, untersucht. Nach Gabe von Ancrod zur Akutbehandlung des Apoplex wurden verminderte neurologische Ausfallerscheinungen bei leicht erhöhter Blutungsneigung beobachtet (Sherman 2002). Allerdings konnte eine weitere klinische Studie mit über 500 Patienten diese Wirkung nicht bestätigen. Levy et al. zogen den Schluss, dass eine intravenöse Gabe von Ancrod bei Schlaganfallpatienten keinen therapeutischen Nutzen erwirkt (Levy et al. 2009). Eine Anwendung zur Behandlung des Hörsturzes erfolgte noch nicht. 


\subsection{Studienziel}

Als potentes Fibrinogenolytikum bietet Ancrod eine Möglichkeit zur pharmakologischen Senkung der Plasmafibrinogenkonzentration. Dies wiederum könnte ein Ansatz zur Behandlung des Hörsturzes sein, da eine pathologisch erhöhte Fibrinogenkonzentration unlängst als ein Risikofaktor für die Entstehung dieser Erkrankung identifiziert wurde (Suckfüll et al. 2002; Mannini et al. 2005). Auch konnte in vivo der Zusammenhang zwischen einer akuten Hyperfibrinogenämie und der Reduktion des cochleären Blutflusses mit konsekutivem Anstieg der Hörschwelle dargestellt werden (Ihler et al. 2012). Das Meerschweinchen-Tiermodell nach Canis et al. erlaubt, den cochleären Blutfluss mittels Intravitalmikroskopie und die Hörschwelle (HS) mittels Hirnstammaudiometrie simultan zu messen (Canis et al. 2010). Unter diesen Voraussetzungen ist es möglich, den CBF und die HS während einer akuten Hyperfibrinogenämie zu analysieren und mögliche Therapiestrategien zur Behandlung des Hörsturzes zu überprüfen.

Im Rahmen dieser Promotionsarbeit sollte die Möglichkeit der medikamentösen Defibrinogenierung zur Behandlung eines vaskulär bedingten Hörverlusts in vivo überprüft werden. Die Auswirkungen der Ancrod-Behandlung auf die Plasmafibrinogenkonzentration, die Hörschwelle sowie Parameter der cochleären Mikrozirkulation wurden untersucht. Da für Patienten keine Untersuchungsmethode zur Bestimmung der cochleären Mikrozirkulation zur Verfügung steht, war Ziel dieser Arbeit, die Auswirkungen einer Senkung der Fibrinogenkonzentration zur Behandlung des Hörsturzes im Tiermodell zu überprüfen. 


\subsection{Materialien}

\begin{tabular}{|c|c|c|}
\hline Blutdruckmessgerät & Samba 201 & $\begin{array}{l}\text { Samba Sensors, Västra Frölunda, } \\
\text { Schweden }\end{array}$ \\
\hline Blutdrucksonde & Samba Preclin 420 & $\begin{array}{l}\text { Samba Sensors, Västra Frölunda, } \\
\text { Schweden }\end{array}$ \\
\hline Chirurgische Naht & $\begin{array}{l}\text { Ethicon Vicryl 5-0 FS-2 at- } \\
\text { raumatisch geflochten }\end{array}$ & $\begin{array}{l}\text { Johnson \& Johnson, Neuss, } \\
\text { Deutschland }\end{array}$ \\
\hline Chirurgische Naht & $\begin{array}{l}\text { Ethicon Sutupak Perma } \\
\text { HandSeide 4-0 geflochten }\end{array}$ & $\begin{array}{l}\text { Johnson \& Johnson, Neuss, } \\
\text { Deutschland }\end{array}$ \\
\hline $\begin{array}{l}\text { Fluoreszeinisothiocya- } \\
\text { nat-Dextran }\end{array}$ & $\begin{array}{l}\text { FITC-Dextran MW } \\
150,000,5 \mathrm{~g} / \mathrm{dl}\end{array}$ & $\begin{array}{l}\text { Sigma-Aldrich, Deisenhofen, } \\
\text { Deutschland }\end{array}$ \\
\hline Heparin & $\begin{array}{l}\text { Heparin Natrium } 25000 \\
\text { ratiopharm }\end{array}$ & $\begin{array}{l}\text { Ratiopharm GmbH, Ulm, Deutsch- } \\
\text { land }\end{array}$ \\
\hline In-Vivo-Mikroskop & Leica M205 FA & $\begin{array}{l}\text { Leica Microsystems, Wetzlar, Ger- } \\
\text { many }\end{array}$ \\
\hline Externe Lichtquelle & Leica EL6000 & $\begin{array}{l}\text { Leica Microsystems, Wetzlar, Ger- } \\
\text { many }\end{array}$ \\
\hline $\begin{array}{l}\text { Software (in vivo-Mik- } \\
\text { roskop) }\end{array}$ & $\begin{array}{l}\text { Leica Application Suite } \\
\text { Software, Version 3.1.2 }\end{array}$ & $\begin{array}{l}\text { Leica Microsystems, Wetzlar, Ger- } \\
\text { many }\end{array}$ \\
\hline Ketamin & KetaVet & $\begin{array}{l}\text { Pfizer Deutschland GmbH, Berlin, } \\
\text { Deutschland }\end{array}$ \\
\hline Lokalanästhetikum & $\begin{array}{l}\text { Ultracain } 2 \% \text {-Suprarenin } \\
5 \mathrm{ml}\end{array}$ & $\begin{array}{l}\text { Sanofi-Aventis Deutschland GmbH, } \\
\text { Frankfurt a.M., Deutschland }\end{array}$ \\
\hline Meerschweinchen & $\begin{array}{l}\text { Weibliche Albino Dunkin } \\
\text { Hartley Meerschweinchen }\end{array}$ & $\begin{array}{l}\text { Harlan Laboratories GmbH, An } \\
\text { Venray, Netherlands; Charles River } \\
\text { Laboratories, Sulzfeld, Germany }\end{array}$ \\
\hline
\end{tabular}




\begin{tabular}{|c|c|c|}
\hline $\begin{array}{l}\text { Nagetierfixiervorrich- } \\
\text { tung }\end{array}$ & Eigenproduktion & \\
\hline Natriumchloridlösung & $\mathrm{NaCl} 0,9 \%$ & Braun, Melsungen, Deutschland \\
\hline Objektiv & $\begin{array}{l}\text { Arbeitsabstand 9,3mm, } \\
\text { NA 0,075 NA, Zeiss Plan- } \\
\text { Neofluar 2,5x/0,075 Pol } \\
1113-113 \infty /-\end{array}$ & $\begin{array}{l}\text { Firma Carl Zeiss, Göttingen, } \\
\text { Deutschland }\end{array}$ \\
\hline Objektiv & $\begin{array}{l}\text { Arbeitsabstand } 21 \mathrm{~mm}, \mathrm{NA} \\
0,35 \mathrm{NA}\end{array}$ & $\begin{array}{l}\text { Firma Olympus, Hamburg, } \\
\text { Deutschland }\end{array}$ \\
\hline Operationsmikroskop & $\begin{array}{l}\text { Leica WILD Heerburg } \\
\text { M650 }\end{array}$ & Leica, Schweiz \\
\hline Polypropylenkatheter & $\begin{array}{l}\text { Portex Polythene Tubing, } \\
\text { Außendurchmesser } \\
0.61 \mathrm{~mm} \text {, Innendurchmes- } \\
\text { ser } 0.28 \mathrm{~mm}\end{array}$ & $\begin{array}{l}\text { Smiths Medical International Ltd, } \\
\text { London, England }\end{array}$ \\
\hline Quecksilberlampe & $\begin{array}{l}\text { 100W Quecksilberlampe, } \\
\text { HBO }\end{array}$ & Osram, München, Deutschland \\
\hline Skalpelle & $\begin{array}{l}\text { Feather disposable Scalpel } \\
\text { No. } 11,15 \text { und } 23\end{array}$ & $\begin{array}{l}\text { Feather Safety Razer Co. Ltd., } \\
\text { Osaka, Japan }\end{array}$ \\
\hline $\begin{array}{l}\text { Videoauswertungspro- } \\
\text { gramm }\end{array}$ & CAP IMAGE & Dr. Zeintl, Heidelberg, Deutschland \\
\hline Hirnstammaudiometrie & GSI Audera & Viasys HealthCare Inc., WI, U.S.A. \\
\hline Spüllösung & $\mathrm{NaCl} 0,9 \%$ & $\begin{array}{l}\text { B. Braun Melsungen AG, Melsun- } \\
\text { gen, Deutschland }\end{array}$ \\
\hline $\begin{array}{l}\text { Graphische Nachbear- } \\
\text { beitung }\end{array}$ & Adobe Illustrator & $\begin{array}{l}\text { Adobe Systems Software Ireland Li- } \\
\text { mited, Dublin, Republic of Ireland }\end{array}$ \\
\hline Statistik-Software & Statistica & $\begin{array}{l}\text { Statista GmbH, Hamburg, Deutsch- } \\
\text { land }\end{array}$ \\
\hline $\begin{array}{l}\text { Statistik- und Analyse- } \\
\text { Software }\end{array}$ & Sigma Plot & $\begin{array}{l}\text { Systat Software GmbH, Erkrath, } \\
\text { Deutschland; Dell Statistica Version } \\
12 \text { (Dell, Round Rock, TX) }\end{array}$ \\
\hline
\end{tabular}




\subsection{Methoden}

\subsubsection{Tiermodell}

Für die Versuchsreihe wurden 15 weibliche Albino Dunkin-Hartley Meerschweinchen verwendet (Harlan Laboratories GmbH, An Venray, Niederlande; Charles River Laboratories, Sulzfeld, Deutschland). Das Gewicht der Tiere betrug zwischen $250 \mathrm{~g}$ und $470 \mathrm{~g}$. Die Tiere wurden präoperativ auf intakte und entzündungsfreie Gehörgänge und Trommelfelle untersucht, sie mussten ebenfalls einen positiven Ohrmuschel-Reflex zeigen.

\subsubsection{Genehmigung des Tierversuchsvorhabens}

Nach $\S 8$ Abs. 1 des Tierschutzgesetzes wurde eine Genehmigung zur Durchführung des Tierversuchsvorhabens beim Niedersächsischen Landesamt für Verbraucherschutz und Lebensmittelsicherheit (LAVES, Oldenburg) beantragt und am 24.01.2013 unter dem Aktenzeichen 33.9-42502-04-12/1011 genehmigt.

\subsection{Präoperative Maßnahmen und Narkose}

Zur Narkoseeinleitung wurde den Meerschweinchen initial eine i.m.-Injektion eines Gemischs aus Xylazin ( $8,5 \mathrm{mg} / \mathrm{kg} \mathrm{KG}$ ) und Ketamin ( $85 \mathrm{mg} / \mathrm{kg} \mathrm{KG}$ ) appliziert. Die Injektion erfolgte in die Oberschenkelmuskulatur des linken Beins. Im Verlauf der Operation wurde die Anästhesie mit der Hälfte oben genannter Dosis und variabler Injektionslokalisationen (z.B. contralaterale Oberschenkelmuskulatur, Oberarmmuskulatur) halbstündlich wiederholt. Dieses Anästhesieprotokoll stellt eine auf Meerschweinchen zugeschnittene Variante der so genannten „Hellabrunner Mischung“ dar, welche in der Veterinärmedizin etabliert ist. Die Spontanatmung bleibt hierbei erhalten.

Zur Ruhigstellung wurden die spontan atmenden Versuchstiere in einen Fixateur eingebracht, der je nach erforderlichem Sicht- und Operationsfeld drei Positionen zuließ: Bauch-, Rückenund Seitlage. Nach Fixierung wurde lokal an Vertex, Processus mastoideus und der Rücken- 
muskulatur auf Höhe der letzten Lenden- und ersten Kreuzwirbel mittels Ultracain 2 \%-Suprarenin anästhesiert, um die Perkutansonden, die als Ableitungselektroden fungieren, an eben genannten Regionen schmerzfrei anbringen zu können.

Im Rahmen der präoperativen Vorbereitung wurde das Operationsfeld zirkulär um das Ohr, am Hals und am rechten Oberschenkel rasiert.

\subsection{Chirurgischer Zugang und Präparation}

\subsubsection{Chirurgische Zugänge}

Nach Hautschnitt am Hals erfolgte eine Spaltung der Fascia colli zur Darstellung der V. jugularis, die nach cranial mittels einer Ligatur abgebunden und anschließend perforiert wurde (wie unten beschrieben). Ein weiterer Hautschnitt wurde angelegt, um die A. femoralis freizulegen. Nach Entfernung der Tunica adventitia wurde das Gefäß zum Zwecke der Erhebung des arteriellen Mitteldrucks punktiert.

Nach Inspektion des äußeren Ohrs wurde nach großzügiger Lokalanästhesie ein sichelförmiger Schnitt periaurikulär geführt und das linke Ohr unter größtmöglicher Schonung der Gefäße abgesetzt. Unter Einsatz eines Bipolar-Elektrokauters wurden die Blutungen gestillt, die Muskulatur wurde entfernt und das Os temporale dargestellt. Dieses wurde eröffnet, das Trommelfell und die Gehörknöchelchen entfernt und die Öffnung erweitert, bis eine ausreichende Darstellung der Cochlea gegeben war (Bild 1). 


\subsubsection{Präparation der Cochlea}

Die Cochlea wurde in der Region der basalen Windung unter bestmöglicher Schonung der Stria vascularis quadratisch gefenstert (Seitenlänge ca. $150 \mu \mathrm{m}$ ), indem mit einem Skalpell Nr. 11 Sollbruchstellen in das knöcherne Gewebe geritzt wurden und im Anschluss das Knochenfenster mit der Spitze des Skalpells abgehoben wurde (Abbildung 1, Abbildung 2).

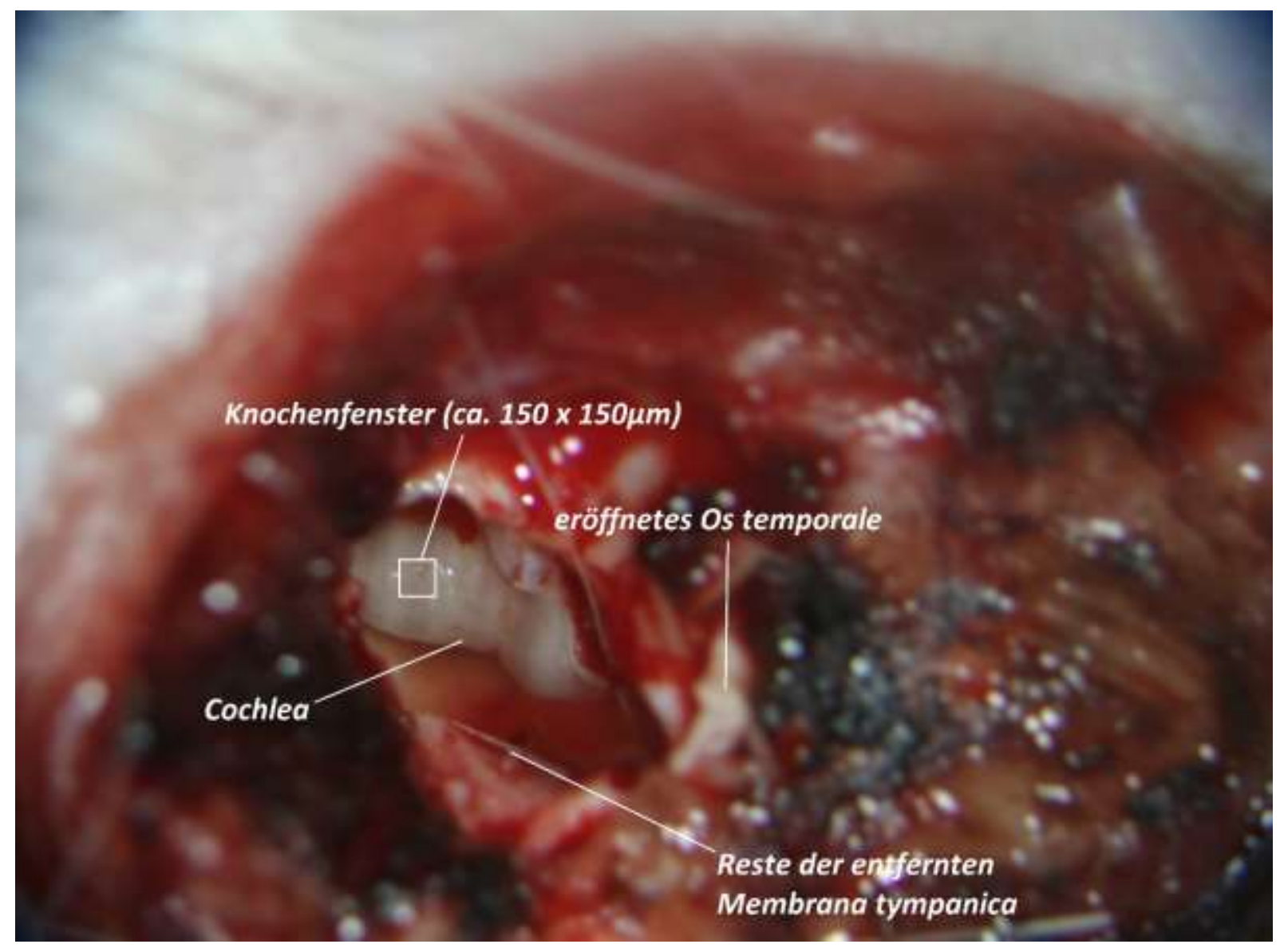

Abbildung 1: Operationssitus nach Präparation der Cochlea und der Fensterung ihrer mittleren Windung. 


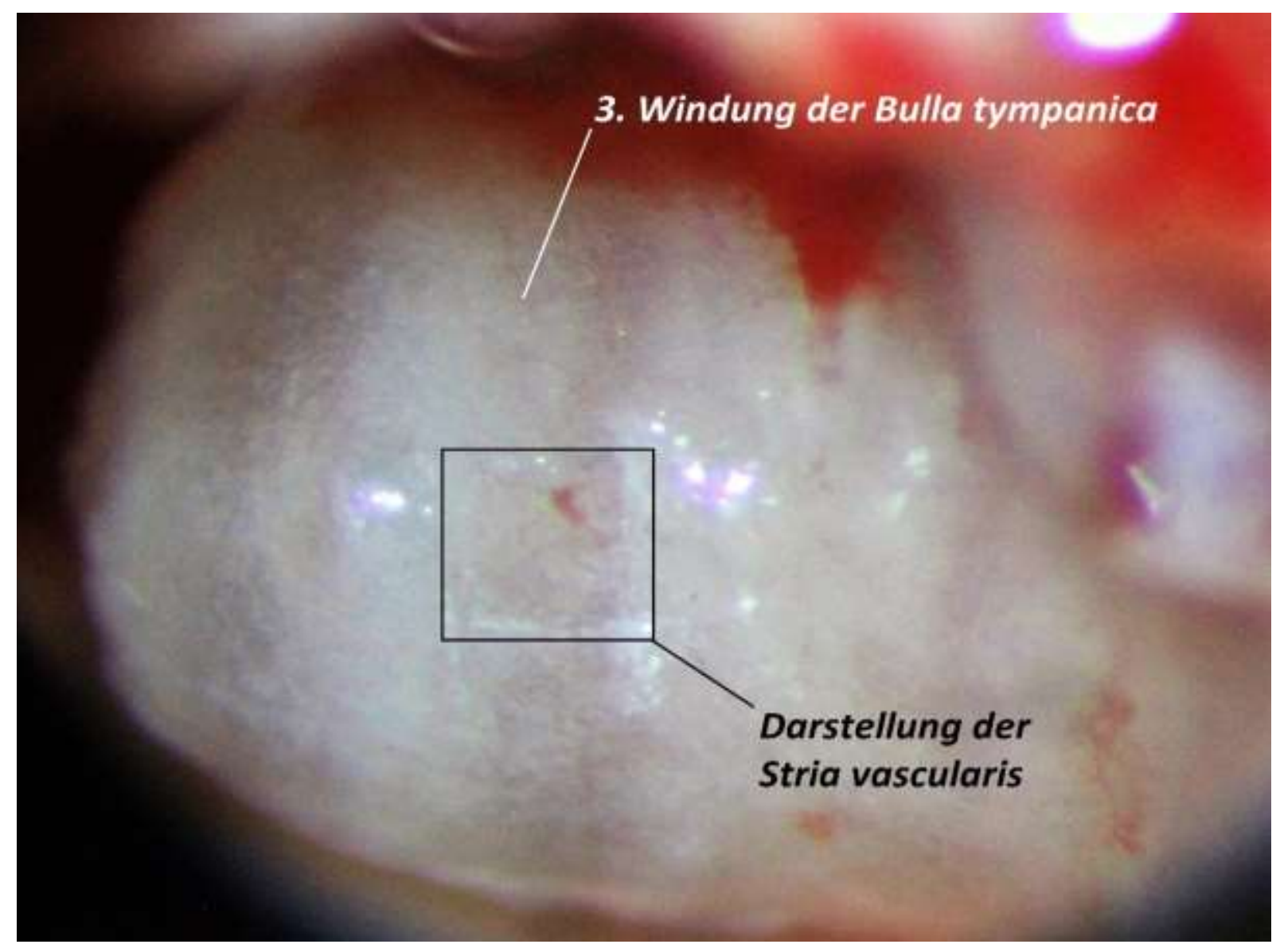

Abbildung 2: Vergrößerte Ansicht auf das Knochenfenster in der 3. Windung der Cochlea. Die Markierung hebt die diskret erkennbare Stria vascularis hervor.

\subsubsection{Arterielle und venöse Zugänge}

In die Jugularvene wurde nach Perforation der Venenwand ein zentralvenöser Katheter (ZVK) aus Polypropylen (Innendurchmesser: 0,28 mm, Außendurchmesser: 0,61 mm) eingeführt und bis in die obere Hohlvene vorgeschoben. Dadurch war es möglich, im Verlauf des Experiments Substanzen zu applizieren, wie auch konstant Blutproben von ausreichender Menge zu entnehmen.

Zur Überwachung des Kreislaufs wurde eine hochauflösende Faseroptiksonde (Samba Preclin 420, $\varnothing 0,42 \mathrm{~mm}$, Samba Sensors, Västra Frölunda, Schweden), verbunden mit einer Kontrolleinheit (Samba 201, Samba Sensors, Västra Frölunda, Schweden), in die A. femoralis eingebracht, welche die Messung des arteriellen Mitteldrucks ermöglichte (Abbildung 3).

Alle chirurgischen Eingriffe wurden mit Hilfe des Operationsmikroskops (Leica WILD Heerburg M650, Leica, Schweiz) durchgeführt. 


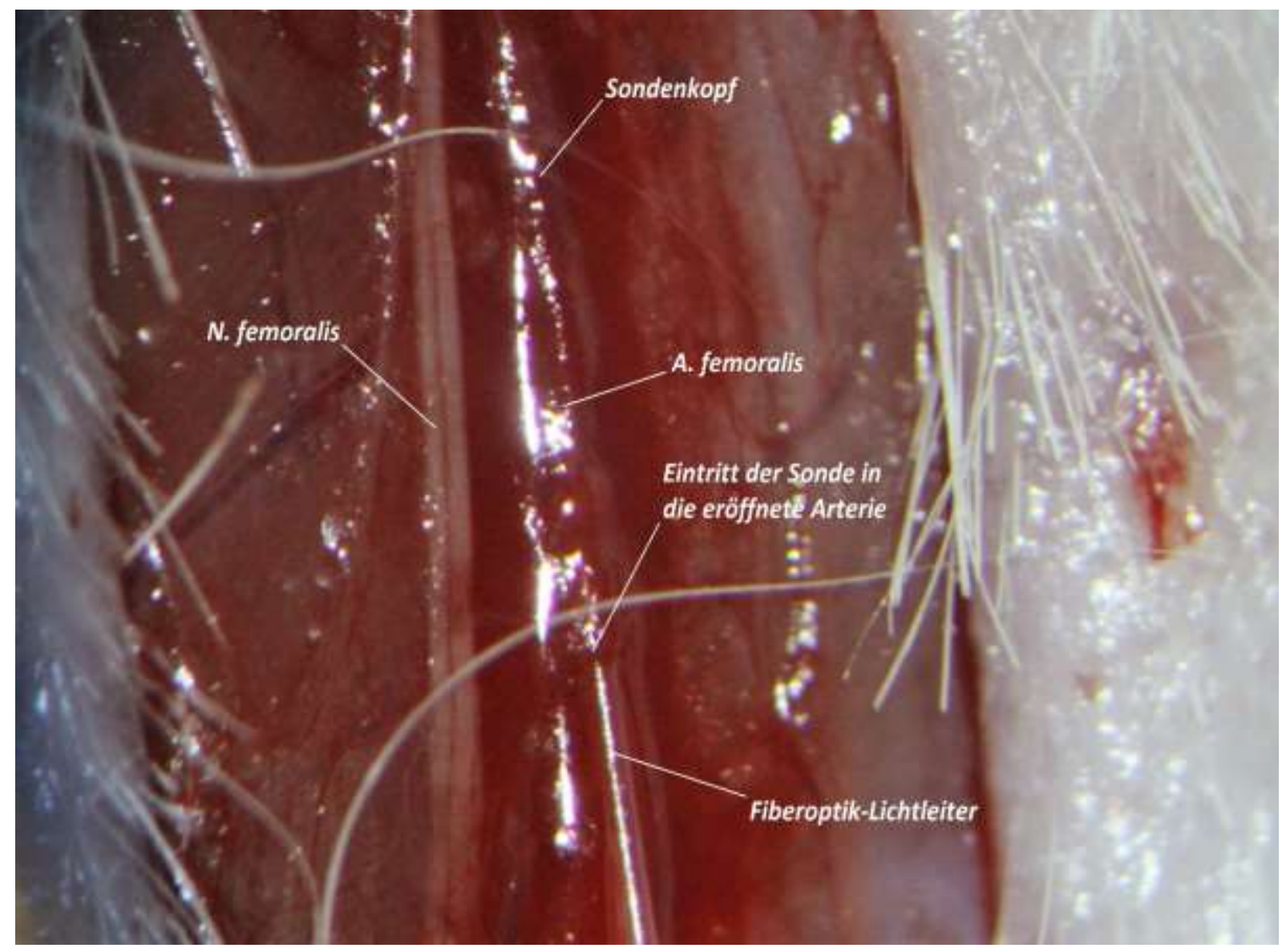

Abbildung 3: In der rechten A. femoralis liegende Faseroptiksonde der Firma Samba $(\varnothing 0,42 \mathrm{~mm})$.

\subsection{Monitoring und intraoperative Messungen}

\subsubsection{Bestimmung des arteriellen Mitteldrucks}

Während der gesamten Versuchsdauer wurden zur Überwachung der Vitalfunktionen der Blutdruck und die Herzfrequenz der Versuchstiere aufgezeichnet. Der arterielle Mitteldruck wurde mittels intraarterieller Blutdrucksonde (Samba Preclin 420, $\varnothing 0,42 \mathrm{~mm}$, Samba Sensors, Västra Frölunda, Schweden) gemessen. Die hochauflösende Fiberoptiksonde gab Auskunft über den Kreislaufzustand der Tiere in Echtzeit. 


\subsubsection{Bestimmung der Hörschwelle mittels Hirnstammaudiometrie (BERA)}

Mittels Hirnstammaudiometrie wurden die frühen akustisch evozierten Potentiale der Hörbahn abgeleitet. Durch abnehmende Reizlautstärke wurde im Rahmen der Untersuchungen die Schwelle des Hörvermögens der Tiere gemessen. Dieses objektive Verfahren ermöglicht es auch unter Sedierung oder Narkose die Hörschwelle zu bestimmen.

Durch Platzierung der Ableitungselektroden (Perkutansonden) an Vertex (Negativsonde), Processus mastoideus (Positivsonde) und wirbelsäulennaher Muskulatur (Erdung) und elektrischem Widerstandstest zur Kalibrierung der Geräte wurden die elektrischen Reaktionen auf Klickreize am rechten Ohr gemessen. Die Software Audera verarbeitete die Potentiale und wandelte sie für jeden Schalldruckpegel in jeweils eine Kurve um. Jede Kurve zeigte fünf Wellen in einem biaxialen Koordinatensystems (X-Achse: Latenzzeit [ms], Y-Achse: Spannung $[\mu \mathrm{V}])$. Eine Welle bildet die Spannung der aufsummierten elektrischen Potentiale entlang der Hörbahn ab, die durch Klick-Geräusche in der Cochlea entstehen. Als Referenzwelle diente Welle III (Jewett und Williston 1971), die die Summenpotentiale der zweiten Neurone darstellt. Ein positiver Höreindruck wurde durch eine Differenz der Amplituden von mindestens $0,03 \mu \mathrm{V}$ definiert. Bei einer Frequenz von $8000 \mathrm{~Hz}$ wurden die Klickreize mit einer Wiederholungsrate von $20,1 \mathrm{~Hz}$ in das rechte Ohr übertragen. Die Messung begann bei einem Schalldruckpegel von $70 \mathrm{~dB}$, absteigend in dekadischen Stufen bis $30 \mathrm{~dB}$, danach in Schritten von 5 $\mathrm{dB}$ bis auf $0 \mathrm{~dB}$ (Abbildung 4). 


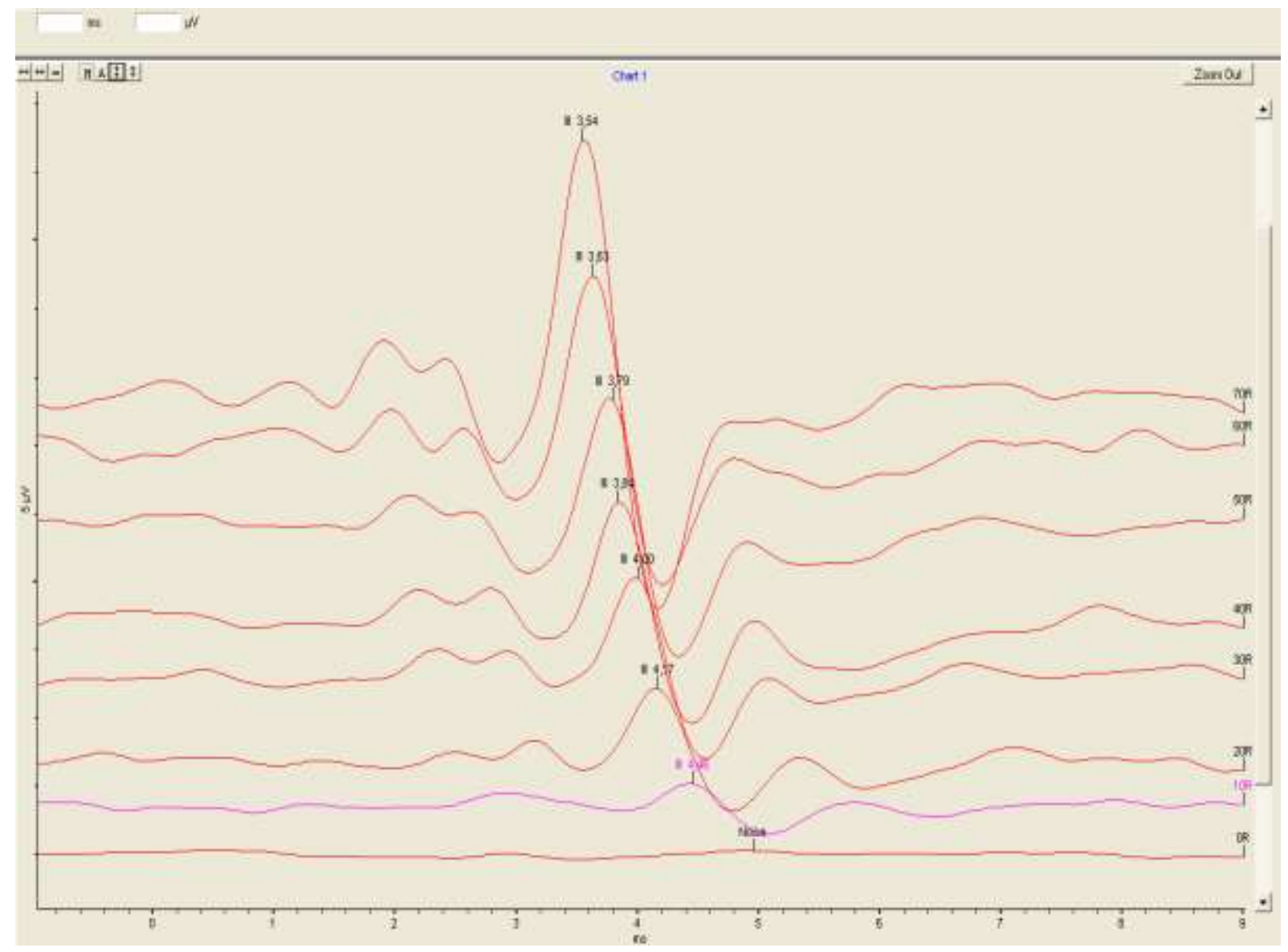

Abbildung 4: Ansicht einer ausgewerteten exemplarischen BERA. Markiert sind alle Kurven, die eine Welle III mit mindestens 0,03 $\mu \mathrm{V}$ Amplitude beinhalten. Farbig abgehoben ist die Kurve der geringsten Dezibel-Einstellung, die dieses Kriterium erfüllt und somit die Hörschwelle darstellt.

\subsubsection{Bestimmung der Fibrinogenkonzentration}

Um die Plasmafibrinogenkonzentration zu messen, wurden Blutproben über den ZVK entnommen, in 0,5 ml Citratröhrchen der Firma Sarstedt überführt und für 10 Minuten bei 2,2 G und $20^{\circ} \mathrm{C}$ zentrifugiert, um das Plasma von den festen Blutbestandteilen zu trennen. Das gewonnene Citratplasma wurde für die weitere Fibrinogenkonzentrationsbestimmung abpipettiert. Im Labor wurde das Fibrinogen mittels quantitativer Bestimmung durch das Analysegerät $A C L$ Top (Instrumentation Laboratory, Mailand, Italien) nach der Methode von Clauss gemessen (Clauss 1957). 


\subsubsection{Bestimmung des cochleären Blutflusses}

Im Bereich der 3. Windung der Cochlea wurde die Stria vascularis durch das zuvor präparierte Knochenfenster unter Verwendung eines Stereomikroskops (Leica M205 FA, Leica Microsystems, Wetzlar, Germany) mit externer Lichtquelle (Leica EL6000, Leica Microsystems, Wetzlar, Germany) und einem Filterblock (Anregung 450 - 490 nm, Emission > 515 nm) intravitalmikroskopisch untersucht. Hierzu wurde zur Visualisierung des Erythrozytenflusses der Gefäße 0,1-0,2 $\mathrm{ml}$ des Plasmamarkers Fluoresceinisothiocyanat 5 \% (FITC) über den ZVK appliziert. Fluorescein ist ein Farbstoff aus der Gruppe der Xanthenfarbstoffe. Wird dieser mit blauem Licht angeregt, reflektiert er grünes Licht. Durch die Konjugation mit 150 kDa Dextran, wird die Wahrscheinlichkeit der Diffusion durch die Gefäßwände maximal geringgehalten. Somit verbleibt das konjugierte FITC als Plasmamarker im Gefäßsystem der Tiere, ohne in die Erythrozyten zu diffundieren. Auf diese Weise erschien das Blutplasma grün fluoreszierend, während die Bereiche der Erythrozyten dunkel verblieben. In einem definierten Bildausschnitt (500 $\mu \mathrm{m} \times 500 \mu \mathrm{m})$ wurden mittels einer Software (Leica Application Suite Software, Version 3.1.2, Leica Microsystems, Wetzlar, Germany) Videos des cochleären Blutflusses für eine spätere optische Auswertung der Erythrozytenfließgeschwindigkeit angefertigt (Abbildung 5). 


\section{Knochenfenster}

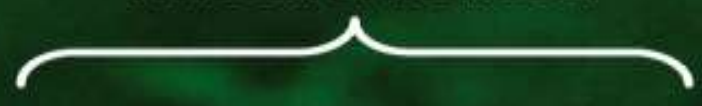

\section{Präkapillare}

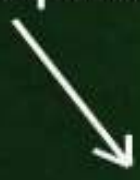

\section{Stria vaskularis}

Abbildung 5: Ansicht der Stria vascularis der 3. Windung der Hörschnecke von Meerschweinchen unter dem Intravitalmikroskop. Helle Passagen zeigen das Plasma, dunkle Passagen die Erythrozyten.

Die Quantifizierung der cochleären Mikrozirkulation erfolgte mithilfe der Software Caplmage

(Dr. Zeintl Biomedical Engineering, Heidelberg, Germany). Hierbei wird mit dem Cursor am Standbild eines Videos eine Linie an einem Gefäß angelegt, die senkrecht zu den Gefäßwänden ist und somit den Durchmesser darstellt. Weiterhin wird eine Linie längs dieses Gefäßes gezogen (Bild 6). Wird die Messung gestartet, werden über eine definierte Zeit die hellen und dunklen Anteile, die den (durch die Längslinie vorgegebenen) Gefäßabschnitt passieren, bestimmt. Die helleren Passagen stehen hierbei für das Plasma, die anderen für die Erythrozyten. Diese Frame-to-Frame-Methode wurde angewandt nach der Beschreibung durch Zeintl et al. (Zeintl et al. 1989).

Zur Auswertung wird von der Software ein Punktdiagramm ausgegeben, in dem alle Pixel in der jeweiligen Helligkeitsstufe erfasst sind. Eine Achse beschreibt die Zeit, die andere den Gefäßabschnitt. Wenn ein heller Pixel (fluoreszierendes Material) das Gefäß durchfließt, zeigt 
sich das in Form eines Striches mit hoher oder niedriger Steigung. Die Steigung wird durch die Geschwindigkeit beeinflusst.

Im Rahmen der Untersuchungen wurde der CBF anhand der Auswertung zweier Kapillaren der Stria vascularis ermittelt. Mehr als zwei Gefäße sind nicht regelmäßig in einer Ebene der Stria vascularis und können daher nicht zeitgleich mikroskopisch fokussiert werden. Für die Auswertung wurde die Formel von Baker und Wayland angewandt (Baker und Wayland 1974): $q=(v / 1.6) \times(d / 2)^{2} \times \pi$. Dabei steht „ $q$ “ für den cochleären Blutfluss, „v“ für die Erythrozytenfließgeschwindigkeit $[\mu \mathrm{m} / \mathrm{s}]$ und „ $\mathrm{d}^{\prime \prime}$ für den Gefäßdurchmesser $[\mu \mathrm{m}]$. Die Werte des cochleären Blutflusses wurden in Relation zu dem jeweiligen Basalwert gesetzt, und somit die relative Änderung in Prozent bestimmt „Relative Change“ [\%].

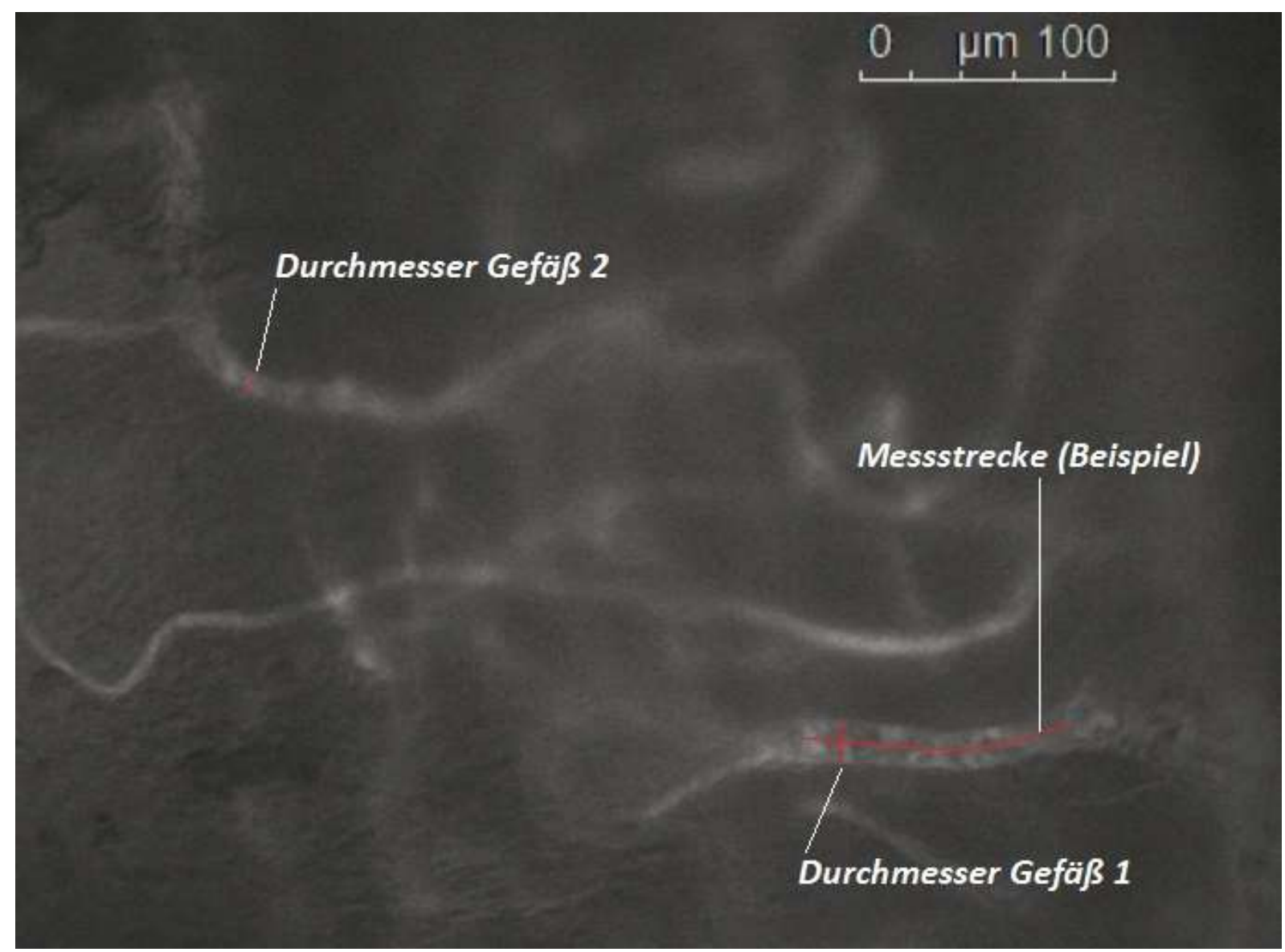

Abbildung 6: Standbild während der Auswertung von Gefäß 1 eines Intravitalmikroskopie-Videos mittels Caplmage. Die Messstrecke definiert die Länge der Gefäßstrecke, über die die hellen und dunklen Anteile während der Auswertung gemessen werden. 


\subsection{Versuchsdesign}

\subsubsection{Verblindung}

In einer Kohorte von 5 Tieren pro Gruppe erfolgte die Behandlung entweder durch die Gabe von Placebo (1 ml/kg Körpergewicht $\mathrm{NaCl}$ 0,9 \%) oder Ancrod (1 ml/kg Körpergewicht bei 10 $\mathrm{U} / \mathrm{ml}$; Nordmark Arzneimittel GmbH \& Co. KG, Uetersen, Deutschland). Zur Verblindung wurden durch einen unabhängigen Untersucher Spritzen mit Injektionslösung vorbereitet, denen entsprechend der Versuchstiere Nummern zugeteilt wurden. Die Entblindung, welches Tier mit welchem Präparat behandelt wurde, erfolgte erst nach kompletter Auswertung aller Daten.

\subsubsection{Bestimmung der Basisparameter}

Nach Platzierung der Messsonden sowie des ZVKs und nach Präparation der Cochlea wurden die Basisparameter (Plasmafibrinogenkonzentration, Hörschwelle und Parameter der Mikrozirkulation) bestimmt. Der arterielle Mitteldruck wurde während des Experiments kontinuierlich aufgezeichnet.

\subsubsection{Induzieren eines plötzlichen Hörverlusts durch Hyperfibrinogenämie}

Um durch eine akute Hyperfibrinogenämie einen plötzlichen Hörverlust zu induzieren, wurde $333 \mathrm{mg} / \mathrm{kg} \mathrm{KG} \mathrm{Fibrinogen,} \mathrm{in} 6 \mathrm{ml}$ 0,9 \%-iger NaCl-Lösung pro $100 \mathrm{mg}$ Fibrinogen gelöst und mittels Perfusor über den ZVK appliziert (1 min/ml). Im Anschluss erfolgte eine erneute Bestimmung der Messparameter. 


\subsubsection{Applikation der Prüfsubstanz}

Die Applikation der Prüfsubstanzen Placebo oder Ancrod erfolgte mittels Injektion aus den von einem unabhängigen Untersucher vorbereiteten Spritzen. Die Injektionsvolumina wurden auf $1 \mathrm{ml} / \mathrm{kg} \mathrm{KG}$ festgelegt, die Ancrod-Gruppe erhielt $10 \mathrm{U} / \mathrm{ml}$, was einer Dosis von $10 \mathrm{U} / \mathrm{kg} \mathrm{KG}$ entspricht. Im Anschluss wurden erneut die PFK, die HS und der CBF gemessen. Diese Parameterbestimmung wurde in einem Abstand von 30 Minuten bis 120 Minuten nach Injektion der Wirkstoffe sequentiell durchgeführt.

Eine schematische Darstellung des Versuchsdesigns dieser Therapiestudie zeigt Abbildung 7.

\begin{tabular}{|l|l|}
\hline $\begin{array}{l}\text { Induzieren } \\
\text { eines } \\
\text { Hörverlusts }\end{array}$ & $\begin{array}{l}\text { Behandlung des } \\
\text { Hörverlustes }\end{array}$ \\
\hline
\end{tabular}

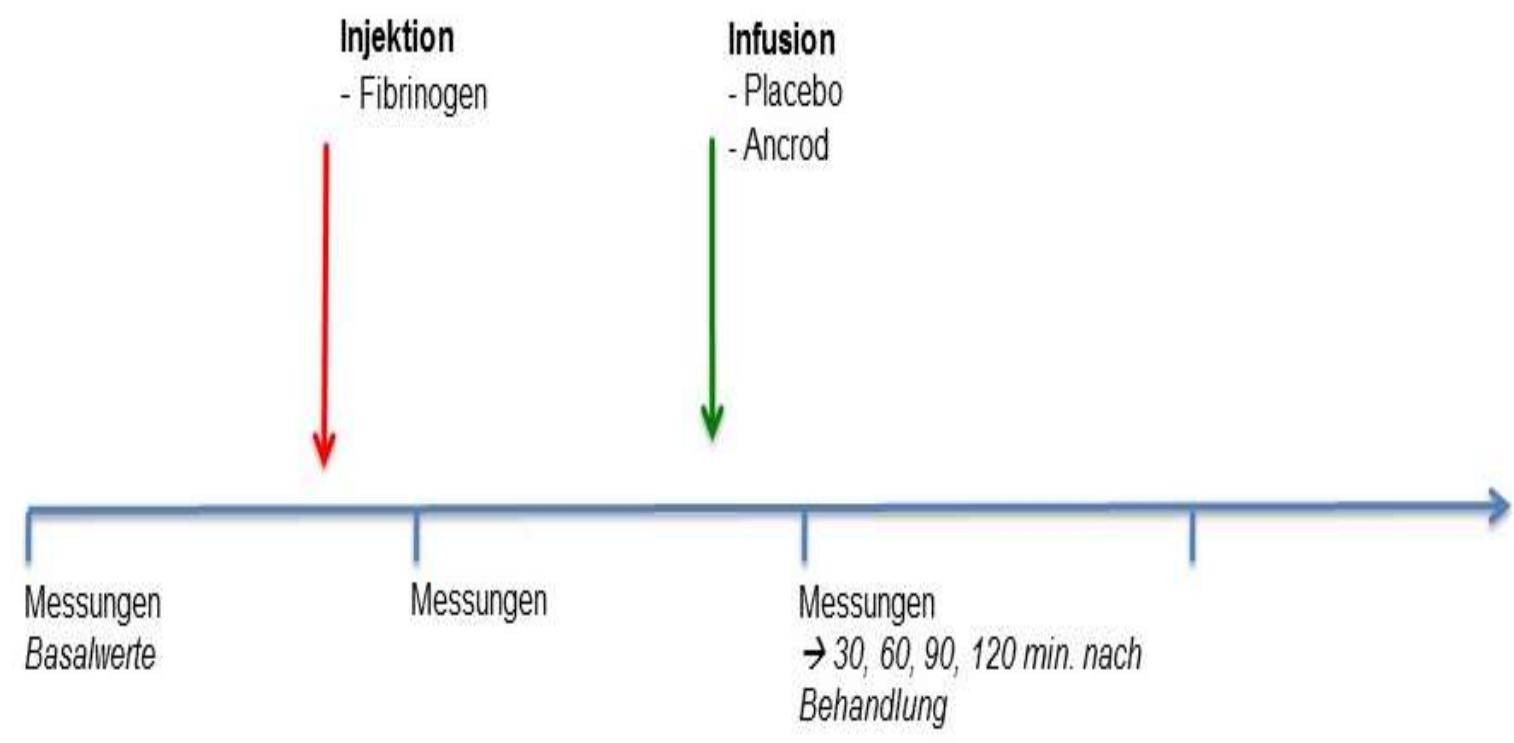

Abbildung 7: Schematische Darstellung der chronologischen Abfolge der Messungen und Applikationen von Substanzen nach der vorbereitenden Operation. 


\subsection{Auswertung}

\subsubsection{Datensammlung}

Die Daten der Hirnstammaudiometrie wurden als Datei der Software Audera gespeichert, zusätzlich auch in JPEGs-Dateien umgewandelt und archiviert. Farbig abgehoben dargestellt wurde die letzte Kurve, deren Welle III eine Differenz von $\geq 0,03 \mu \mathrm{V}$ zur vorherigen Messung mit einem höheren Schalldruckpegel aufwies. Auf diese Weise ist unmittelbar zu erkennen, bei welchem Schalldruckpegel die Hörschwelle erreicht war.

Befundausdrucke der PFK wurden zu jeder Probe durch das Labor der Abteilung für Klinische Chemie, Universitätsmedizin Göttingen (Studienkoordination Jutta Engelmayer) zur Verfügung gestellt.

Mittels Caplmage wurde der Durchmesser zweier Gefäße über eine individuelle Messstrecke ermittelt. Unter Anwendung der Formel nach Baker und Wayland wurde mithilfe der Software Excel (Microsoft Corporation, Redmond, USA) aus Durchmesser und Erythrozytenfließgeschwindigkeit der cochleäre Blutfluss $Q$ für alle jeweiligen Zeitpunkte des Experimentes errechnet (Baker und Wayland 1974). Für jedes Tier galt der Basiswert Q als Referenzpunkt für alle folgenden Werte des CBF, sodass man einen Prozentsatz in Relation zum Ausgangswert erhielt. Alle erhobenen Parameter wurden für jedes Tier in einer Excel-Tabelle dokumentiert.

\subsubsection{Statistik}

Die im Rahmen dieser Dissertationsarbeit dargestellten Experimente und Ergebnisse sind Teil einer Versuchsreihe mit drei Versuchsgruppen. Die statistische Auswertung erfolgte für alle drei Versuchsgruppen mittels Two-Way-ANOVA für wiederholte Messungen. Die in der Arbeit berichteten Ergebnisse der statistischen Auswertung sind Teil des Gesamtergebnisses.

Die graphischen Darstellungen wurde mit der Software Dell Statistica Version 12 (Dell, Round Rock, TX) erstellt und durch Adobe Illustrator (Adobe Systems Software Ireland Limited, Dublin, Republic of Ireland) stilistisch modifiziert. Auf statistische Signifikanz wurde mithilfe der Software SigmaPlot 2004 für Windows Version 12.0 (Systat Software, Chicago, IL, USA) mittels Two-Way-Repeated-Measure-Analysis of Variance (2way RM ANOVA) und einem Bonferroni$\mathrm{t}$-Test getestet. Die Daten werden als Mittelwert \pm Standardabweichung angezeigt. Ein P-Wert $\alpha<0,05$ stellt das Signifikanzniveau dar. 


\section{Ergebnisse}

\subsection{Arterieller Mitteldruck}

Der arterielle Mitteldruck der Placebo-Gruppe liegt vor Injektion gemittelt bei $43,58 \mathrm{mmHg} \pm$ 8,13 (Intervall 32,13-53,86). Im Versuchsverlauf kommt es zu einer Abnahme, zwischen 60 und 90 Minuten zeigt sich eine signifikante Reduktion $(p<0,05)$ von durchschnittlich 39,73 $\mathrm{mmHg} \pm 13,19$ (Intervall 20,53-51,72) auf 26,71 mmHg \pm 6,70 (Intervall 20,52-33,89).

Der arterielle Mitteldruck der Ancrod-Gruppe liegt zu Beginn des Versuchs bei 49,1 mmHg \pm 27,1 (Intervall 28,32-96,57). Nach Fibrinogen-Gabe liegt der Blutdruck bei $51,56 \mathrm{mmHg} \pm$ 20,44 (Intervall 37,2-81,66). Im Verlauf sinkt der Arterielle Mitteldruck bis auf ein Minimum von $17,65 \mathrm{mmHg} \pm 7,71$ (Intervall 8,77-22,64) zum Zeitpunkt 120 Minuten nach Therapie. 
3.2 Veränderung der Messparameter nach Fibrinogeninjektion in der PlaceboGruppe

\subsubsection{Plasmafibrinogenkonzentration}

Nach Injektion von 333 mg Fibrinogen pro kg Körpergewicht zeigt sich eine signifikante Steigerung der PFK $(p<0,01)$ von durchschnittlich $131,8 \mathrm{mg} / \mathrm{dL} \pm 20,8$ (Intervall 110-166) auf $471,8 \mathrm{mg} / \mathrm{dL} \pm 85,34$ (Intervall 345-567). Im weiteren Versuchsverlauf bleibt die Fibrinogenkonzentration des Blutplasmas relativ konstant erhöht. Bei der Messung 120 Minuten nach Placebo-Applikation liegt die Fibrinogenkonzentration bei $422 \mathrm{mg} / \mathrm{dL} \pm 62,22$ (Intervall 378466) und somit 290,2 mg/dL über dem Mittelwert der Basalmessung (Abbildung 8).

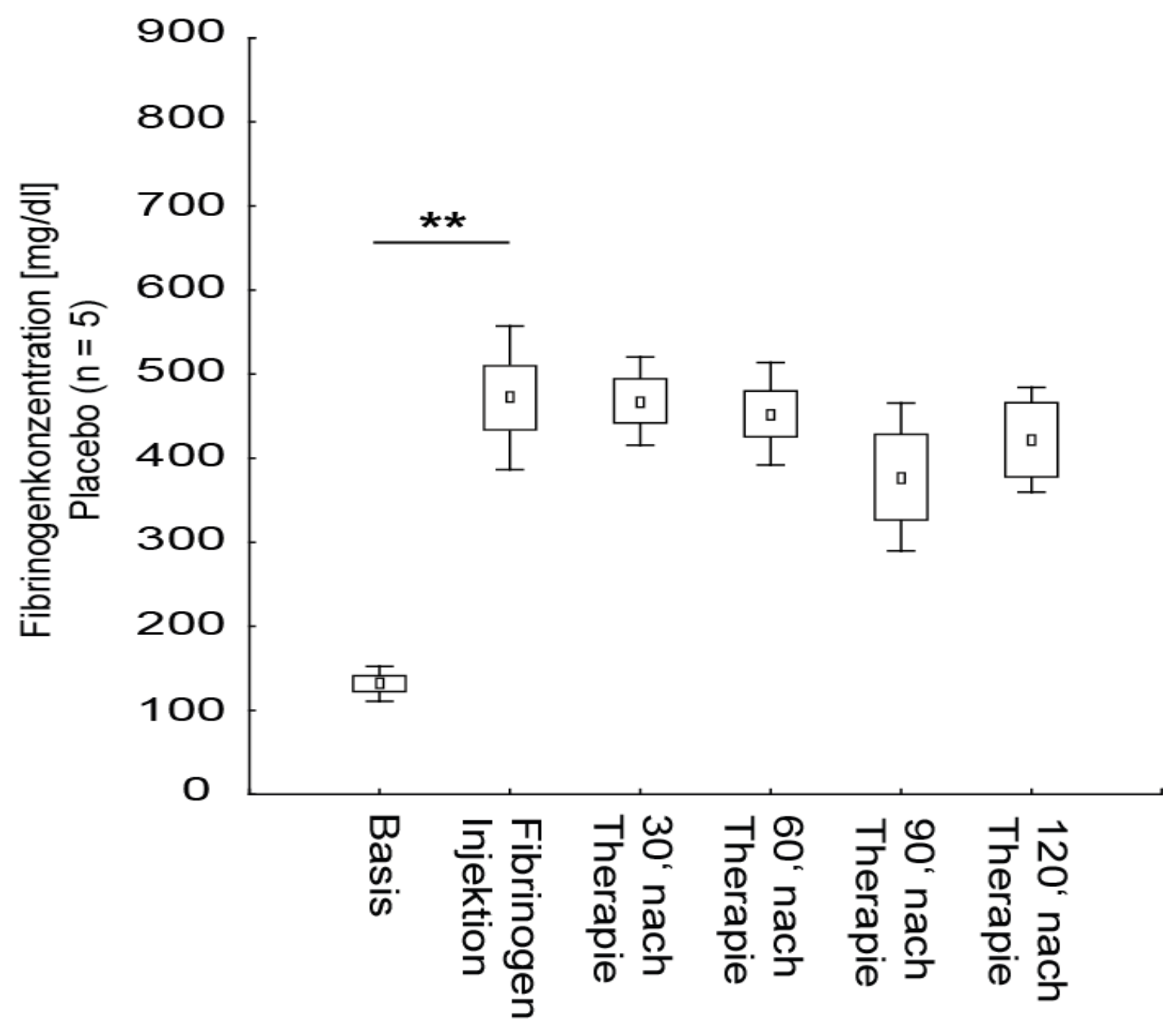

Abbildung 8: Nach Fibrinogen-Injektion kommt es zu einem signifikanten Anstieg der PFK um durchschnittlich $340 \mathrm{mg} / \mathrm{dL}(p<0,01)$. Im weiteren Verlauf des Experiments bleibt die Plasmafibrinogenkonzentration erhöht, übersteigt aber nicht den Wert nach Fibrinogen-Injektion. 


\subsubsection{Hörschwelle (Hirnstammaudiometrie)}

Nach Fibrinogen-Injektion zur Induktion eines akuten vaskulären Hörverlusts steigt die Hörschwelle signifikant $(p<0,01)$ von $16 \mathrm{~dB} \pm 5,48$ (Intervall 10-20) auf $30 \mathrm{~dB} \pm 15,81$ (Intervall 10-50). Im weiteren Verlauf bleiben die Werte im Vergleich zur Basismessung erhöht. Das Minimum wurde 30 Minuten nach Therapie mit $28 \mathrm{~dB} \pm 8,37$ (Intervall 20-40) gemessen, 120 Minuten nach Therapie ergab die Hirnstammaudiometrie eine Hörschwelle von $35 \mathrm{~dB} \pm 7,07$ (Intervall 30-40). Dies entspricht einer Differenz von 19 dB zum Mittelwert der Basalmessung (Abbildung 9).

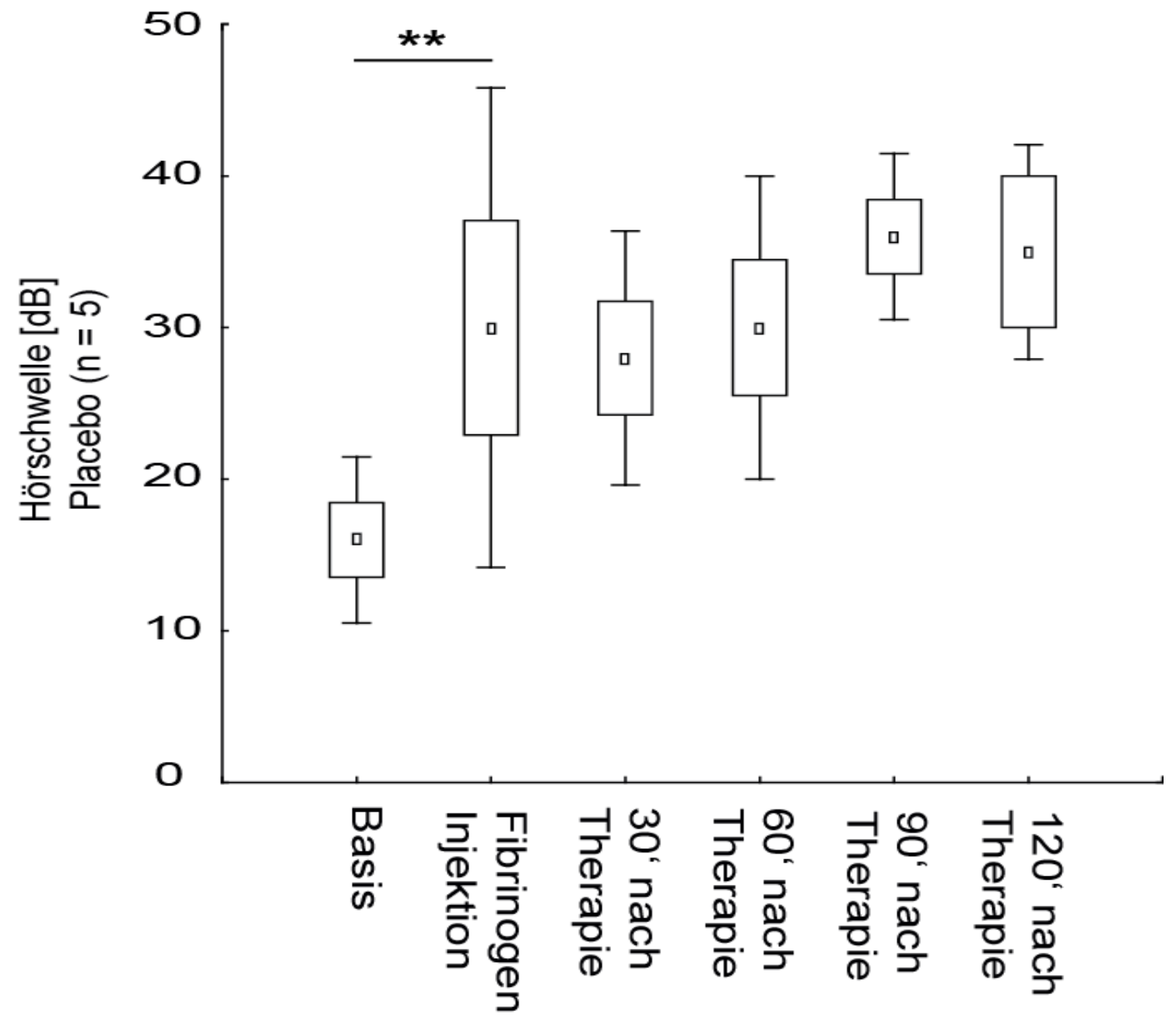

Abbildung 9: Nach Injektion von 333 mg/kg KG Fibrinogen steigt die Hörschwelle signifikant um durchschnittlich $14 d B(p<0,01)$. Es folgt eine nicht signifikante schwankende Erhöhung in den folgenden 120 Minuten mit dem Minimum der Mittelwerte 30 Minuten nach Therapie mit $28 d B \pm 8,37$. 


\subsubsection{Cochleärer Blutfluss}

Nach Fibrinogen-Injektion ist ein klarer Trend zu einer Reduktion der cochleären Durchblutung zu erkennen. 60 Minuten nach Placebo-Injektion liegt der CBF bei $66 \% 28$ (Intervall 0,350,88) des Ausgangswertes. Am Ende des Experiments, 120 Minuten nach Therapie wurden $71 \% \pm 2$ (Intervall 0,70-0,72) des Basiswertes bestimmt (Abbildung 10). Im Rahmen der multiplen Testung einer Versuchsreihe mit drei Versuchsgruppen zeigt diese Reduktion keine statistische Signifikanz (Abbildung 10).

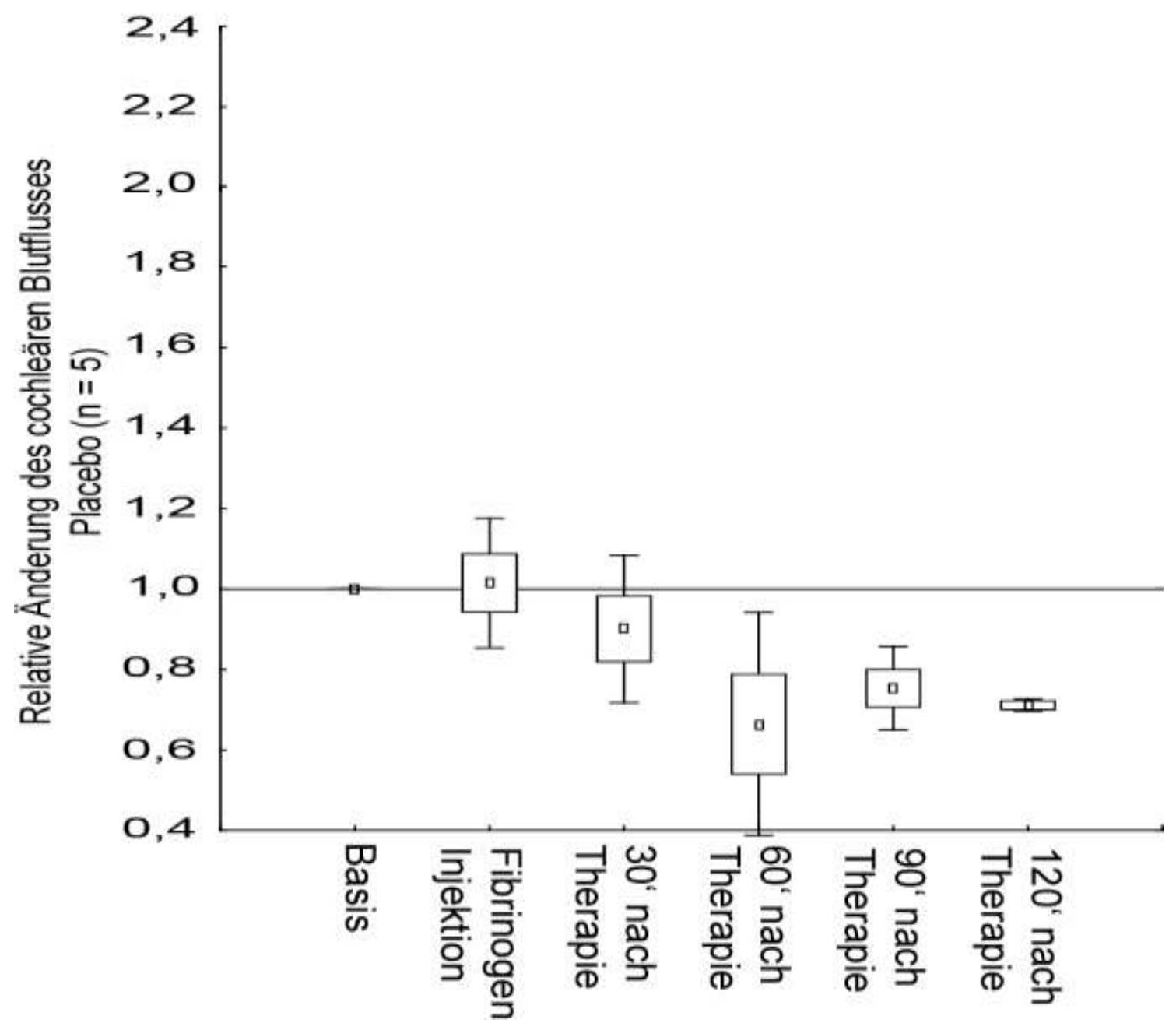

Abbildung 10: Nach Fibrinogen-Injektion ist im Versuchsverlauf eine Reduktion des cochleären Blutflusses zu erkennen. Diese liegt 120 Minuten nach Placebo-Injektion bei 71 \% des Ausgangswertes. 


\subsubsection{Alle Parameter im Vergleich}

Plasmafibrinogenkonzentration und Hörschwelle verzeichnen nach Fibrinogen-Gabe einen signifikanten Anstieg. Diese Erhöhung bleibt während des gesamten Versuchsverlaufs erhalten. Hingegen beschreibt der cochleäre Blutfluss im Verlauf eine deutlich abnehmende Tendenz. Hervorzuheben ist die Gegensätzlichkeit der Entwicklung des cochleären Blutflusses gegenüber der PFK und der HS (Abbildung 11).

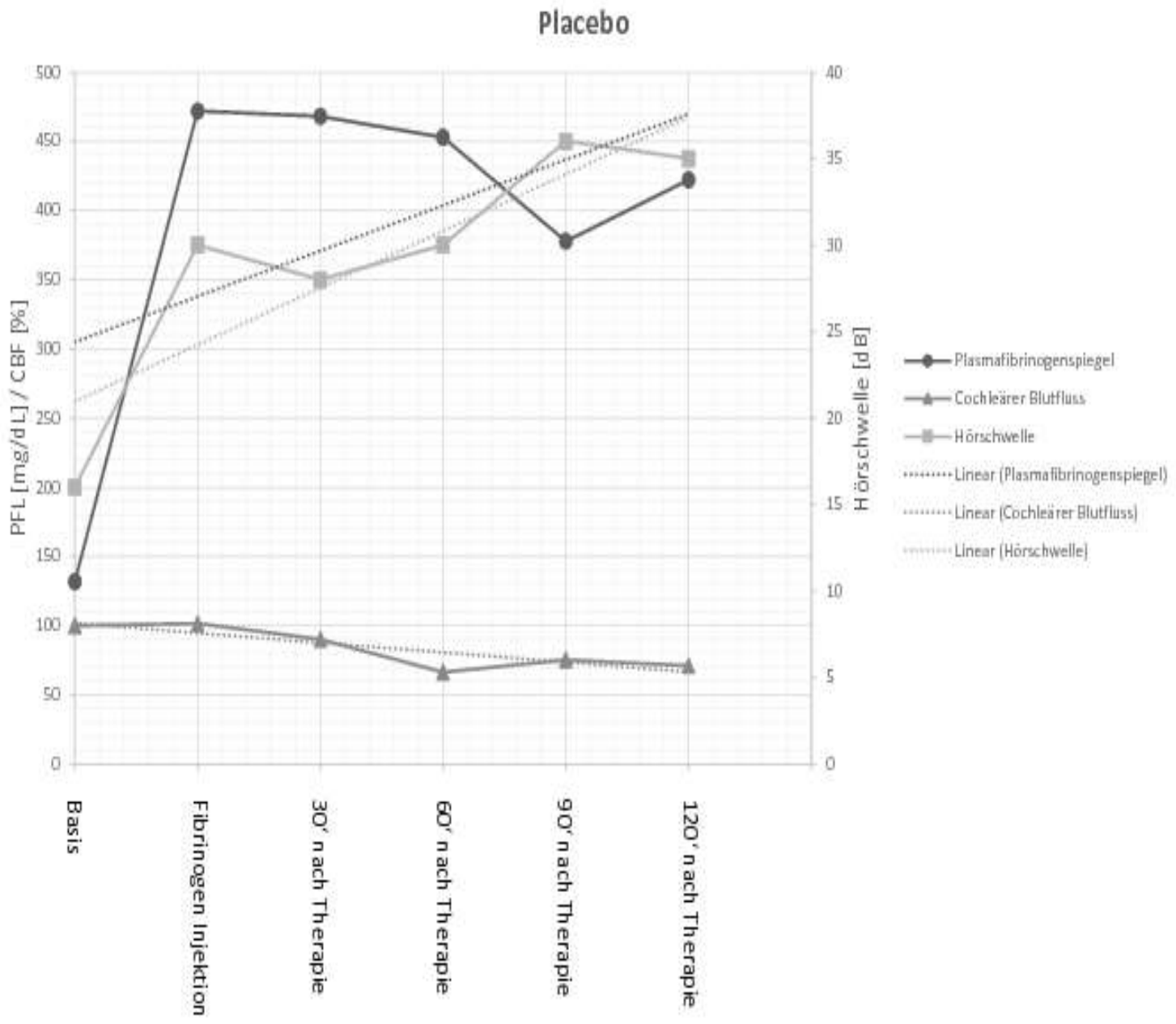

Abbildung 11: Die Parameter Hörschwelle (HS) und Plasmafibrinogenkonzentration (PFL) verzeichnen nach Fibrinogen-Gabe einen Anstieg. Unter Placebobehandlung bleibt dies erhalten. Der cochleäre Blutfluss verhält sich gegensätzlich, er weist nach Fibrinogen-Gabe in Relation zum Basalwert stets geringere Werte auf. Diesen Gegensatz soll die gepunktete lineare Auftragung der Kurven verdeutlichen. 
3.3 Verbesserung des akuten, durch Hyperfibrinogenämie induzierten Hörverlusts unter Ancrodbehandlung

\subsubsection{Plasmafibrinogenkonzentration}

Die Plasmafibrinogenkonzentration steigt nach Injektion von $333 \mathrm{mg} / \mathrm{kg}$ KG Fibrinogen signifikant von durchschnittlich 133,4 mg/dL $\pm 16,95$ (Intervall 115-148) auf 628,6 mg/dL $\pm 247,64$ (Intervall 287-926) an $(p<0,01)$. Dies entspricht einer gemittelten Konzentrationssteigerung von 495,2 mg/dL ( $p<0,01)$. Nach der Gabe von Ancrod sinkt die PFK um durchschnittlich 460,8 $\mathrm{mg} / \mathrm{dL}$ auf $167,8 \mathrm{mg} / \mathrm{dL} \pm 80,04$ (Intervall 61-271). Zu jedem weiteren Messpunkt sind die Werte signifikant niedriger als nach Fibrinogen-Injektion $(p<0,01)$. Zum Zeitpunkt 120 Minuten nach Ancrodgabe erreicht die PFK das Minimum und beträgt im Mittel 91,2 mg/dL \pm 35,07(Intervall 63-153). Dieser Finalwert ist 537,4 mg/dL geringer als der Messwert unmittelbar nach Fibrinogen-Injektion (Abbildung 12). 


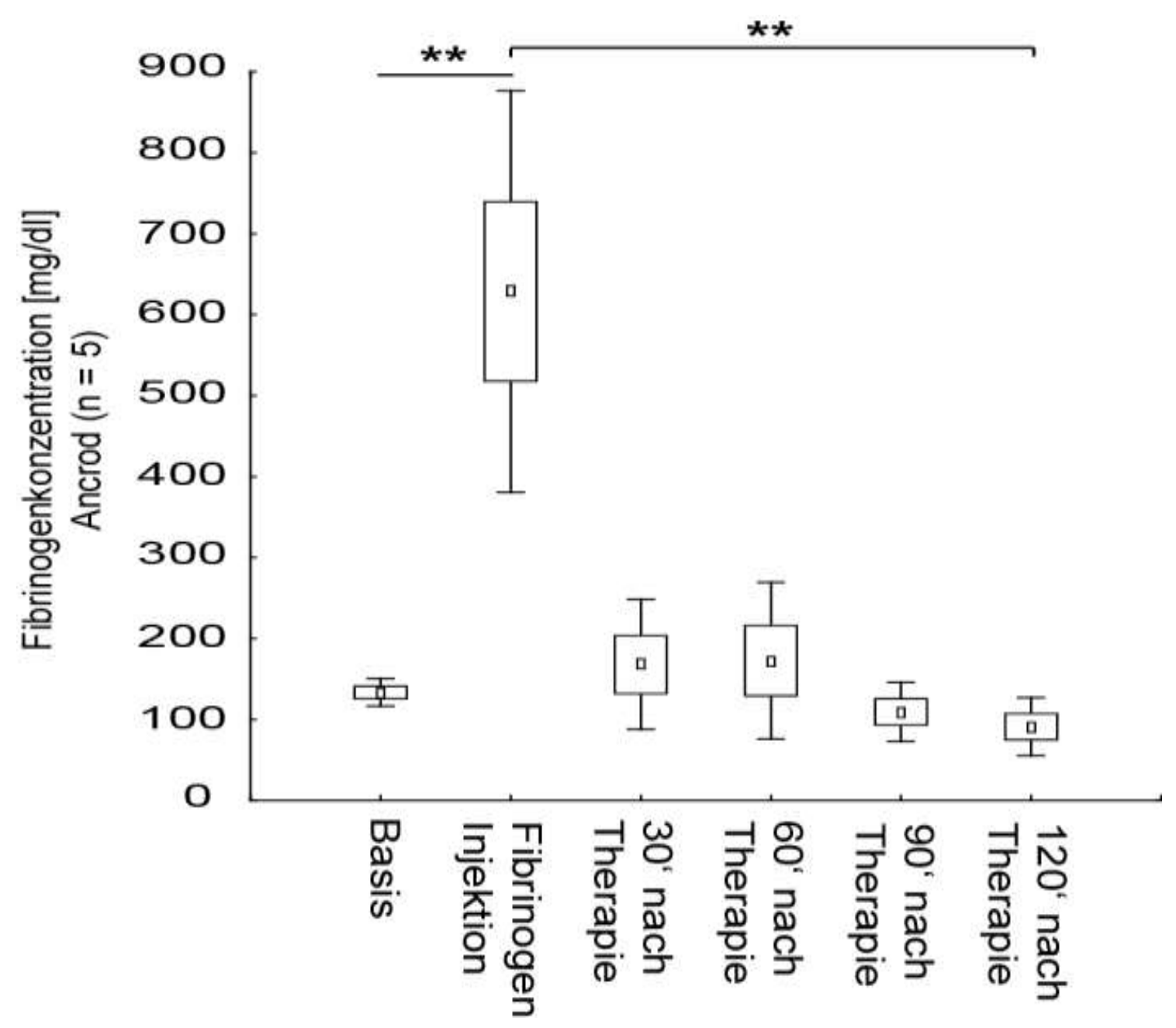

Abbildung 12: Nach Fibrinogen-Injektion steigt die PFK signifikant um 495,2 mg/dL ( $p<0,01)$. Nach der Gabe von Ancrod fällt das Fibrinongen im Blutplasma um 460,8 mg/dL auf 167,8 mg/dL ( $p<0,01)$. Anschließend bleiben die Mittelwerte über die gesamte Dauer des Experiments signifikant geringer gegenüber dem Wert nach FibrinogenInjektion $(p<0,01)$. 


\subsubsection{Hörschwelle (Hirnstammaudiometrie)}

Die HS der Meerschweinchen zeigt sich nach Fibrinogen-Gabe zur Hörsturzinduktion um durchschnittlich $23 \mathrm{~dB}$ erhöht. Sie steigt vom Basiswert $4 \mathrm{~dB} \pm 5,48$ (Intervall 0-10) signifikant auf $27 \mathrm{~dB} \pm 2,74$ (Intervall 25-30) nach Fibrinogen-Injektion $(p<0,01)$. Nach Applikation von Ancrod ist bezogen auf den Messwert nach Fibrinogen-Injektion zu jedem folgenden Messzeitpunkt eine signifikante Verbesserung des Hörvermögens zu verzeichnen (Abbildung 13). 30 Minuten nach Ancrod-Gabe sinkt die HS von $27 \mathrm{~dB} \pm 2,74$ (Intervall 25-30) auf $15 \mathrm{~dB} \pm 3,54$ (Intervall 10-20) $(p<0,05)$. Die Minimalwerte werden mit $10 \mathrm{~dB} \pm 3,54$ (Intervall 5-15) jeweils 60 und 90 Minuten nach Therapie gemessen $(p<0,01)$, final zeigt sich eine HS von $11 \mathrm{~dB} \pm$ 5,48 (Intervall 5-20) $(p<0,01)$.

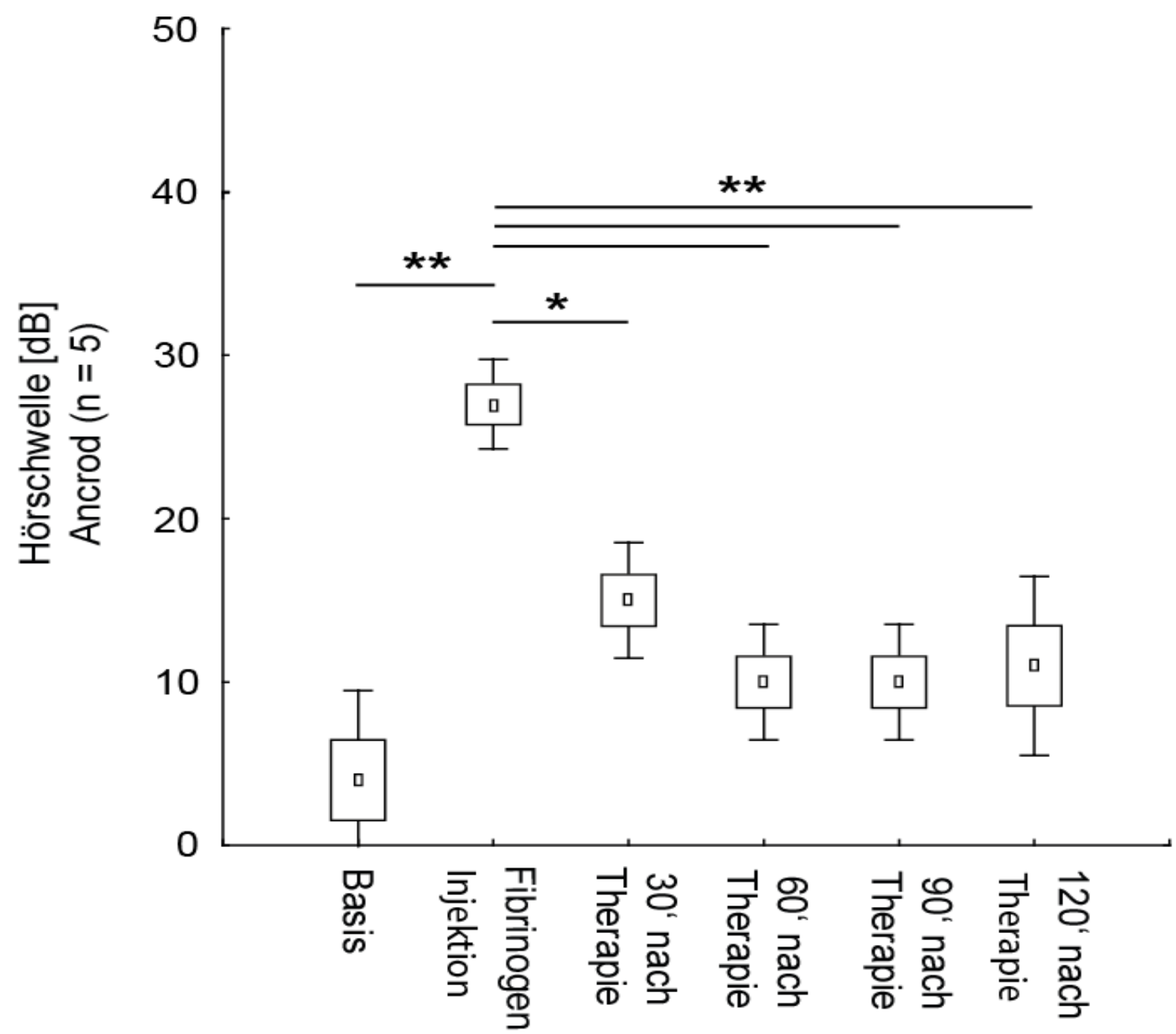

Abbildung 13: Nach Fibrinogen-Gabe steigt die HS signifikant um $23 d B$ auf $27 d B(p<0,01)$. Es folgt eine signifikante Verbesserung auf zunächst durchschnittlich $15 d B 30$ Minuten nach Therapie $(p<0,05)$ und durchschnittlich $10 \mathrm{~dB}$ zu den Messungen 60 und 90 Minuten nach Ancrod-Gabe $(p<0,01)$. Der Wert 120 Minuten nach Therapie ist signifikant niedriger als der Messpunkt nach Fibrinogen-Gabe und liegt bei $11 d B(p<0,01)$. 


\subsubsection{Cochleärer Blutfluss}

Nach Injektion von Fibrinogen zeigt sich mit $79 \% \pm 7,4$ (Intervall 0,72-0,9) des Basiswertes eine sinkende Tendenz des CBF. 30 Minuten nach Applikation von Ancrod kommt es zu einer signifikanten Steigerung auf $119,1 \% \pm 15$ (Intervall 0,96-1,48) des Ausgangswerts $(p<0,05)$. $\mathrm{Zu}$ jedem weiteren Messzeitpunkt lässt sich ebenfalls eine signifikante $(p<0,01)$ Steigerung des CBF in Bezug auf den Wert nach Fibrinogen-Gabe bestimmen (Abbildung 14). Das Maximum findet sich 120 Minuten nach Therapie mit $160 \% \pm 72$ (Intervall 1,11-2,87) CBF im Verhältnis zum Ausgangswert.

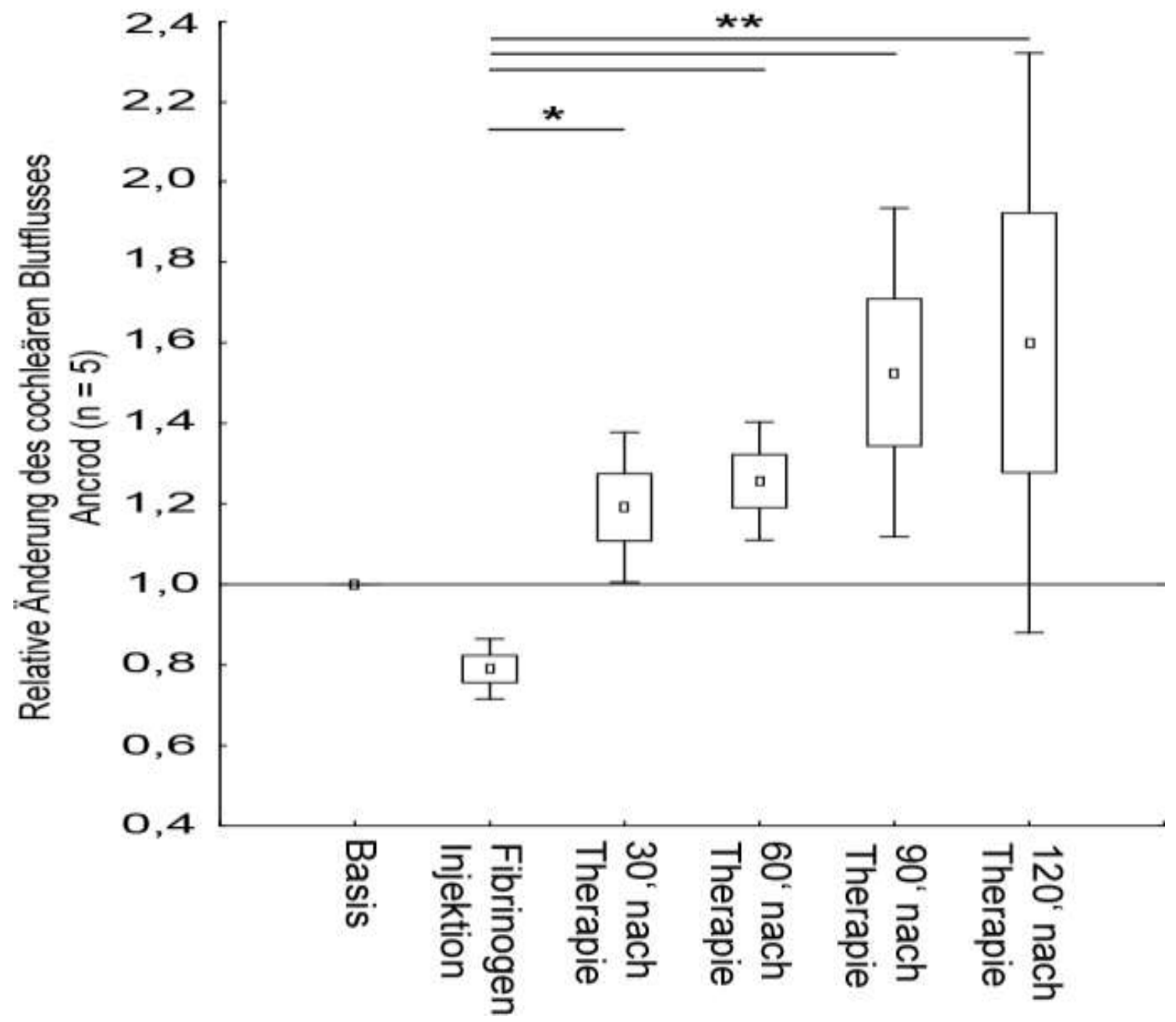

Abbildung 14: Nach Fibrinogen-Injektion zeigt sich eine sinkende Tendenz des CBF um $21 \%$ im Verhältnis zum Ausgangswert. Nach Gabe von Ancrod kommt es zu einem kontinuierlichen Anstieg des cochleären Blutflusses bis auf $160 \%$ des Ausgangswertes. 


\subsubsection{Alle Parameter im Vergleich}

Im Versuchsverlauf kommt es bei Plasmafibrinogenkonzentration und Hörschwelle nach Fibrinogen-Injektion zu einem signifikanten Anstieg gefolgt von einer deutlichen Reduktion nach Applikation von Ancrod. Gegensätzlich dazu verhält sich der cochleäre Blutfluss. Sein Minimum ist zum Messzeitpunkt nach Fibrinogen-Gabe erreicht, nach Therapie mit Ancrod zeigt sich hingegen ein kontinuierlicher Anstieg (Abbildung 15).

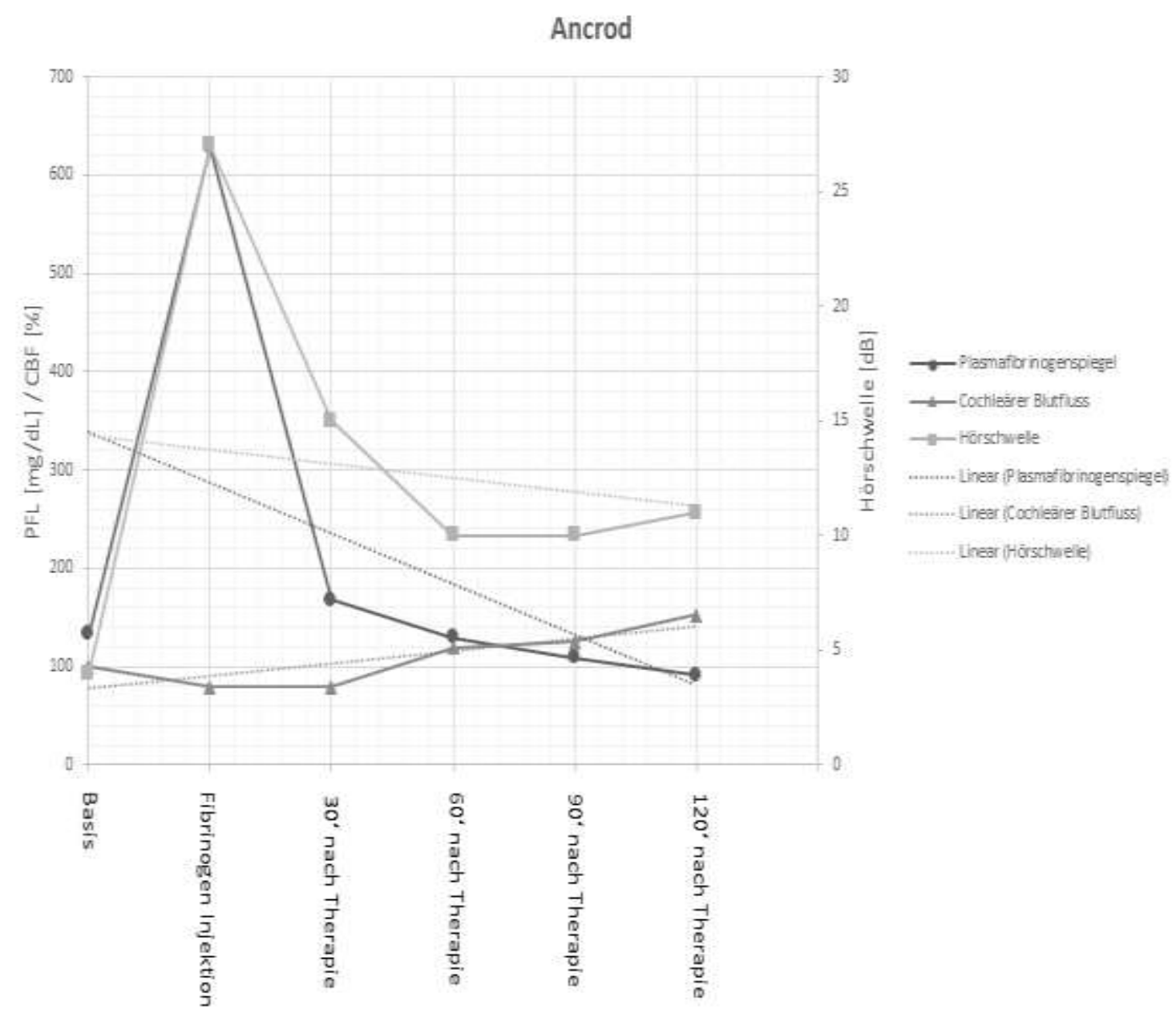

Abbildung 15: Nach Fibrinogen-Gabe steigen die PFK und HS, wohingegen der CBF eine sinkende Tendenz aufweist. Nach Therapie mit Ancrod zeigen PFK und HS sinkende Werte, der CBF hingegen verzeichnet einen Anstieg. 


\subsection{Statistischer Gruppenvergleich (Placebo vs. Ancrod)}

\subsubsection{Plasmafibrinogenkonzentration}

Nach Fibrinogen-Gabe weisen beide Gruppen stark erhöhte Plasmafibrinogenkonzentrationen auf. In der Placebo-Gruppe werden nach Fibrinogen-Injektion gemittelt $471,8 \mathrm{mg} / \mathrm{dL} \pm$ 85,3 (Intervall 345-567) gemessen, der Durchschnittswert der Ancrod-Gruppe liegt zum gleichen Messzeitpunkt bei 628,6 mg/dL $\pm 247,6$ (Intervall 287-926). Nach Applikation von Placebo oder Ancrod liegt zu jedem definierten Zeitpunkt des Versuchs ein signifikanter Unterschied in der Plasmafibrinogenkonzentrationen vor $(p<0,01)$.

\subsubsection{Hörschwelle (Hirnstammaudiometrie)}

Nach Induktion eines akuten Hörverlustes mittels Fibrinogen-Injektion bleibt die Hörschwelle unter der Therapie mit Placebo erhöht, wohingegen die Ancrod-Behandlung eine Reversibilität der Hörstörung zur Folge hat. Bereits 30 Minuten nach Infusion der Wirkstoffe zeigt sich im Vergleich der beiden Therapiegruppen ein signifikanter Unterschied (30 Minuten Messzeitpunkt $p<0,05$, Messzeitpunkte 60-120 min nach Therapie $p<0,01$; Abbildung 16). 


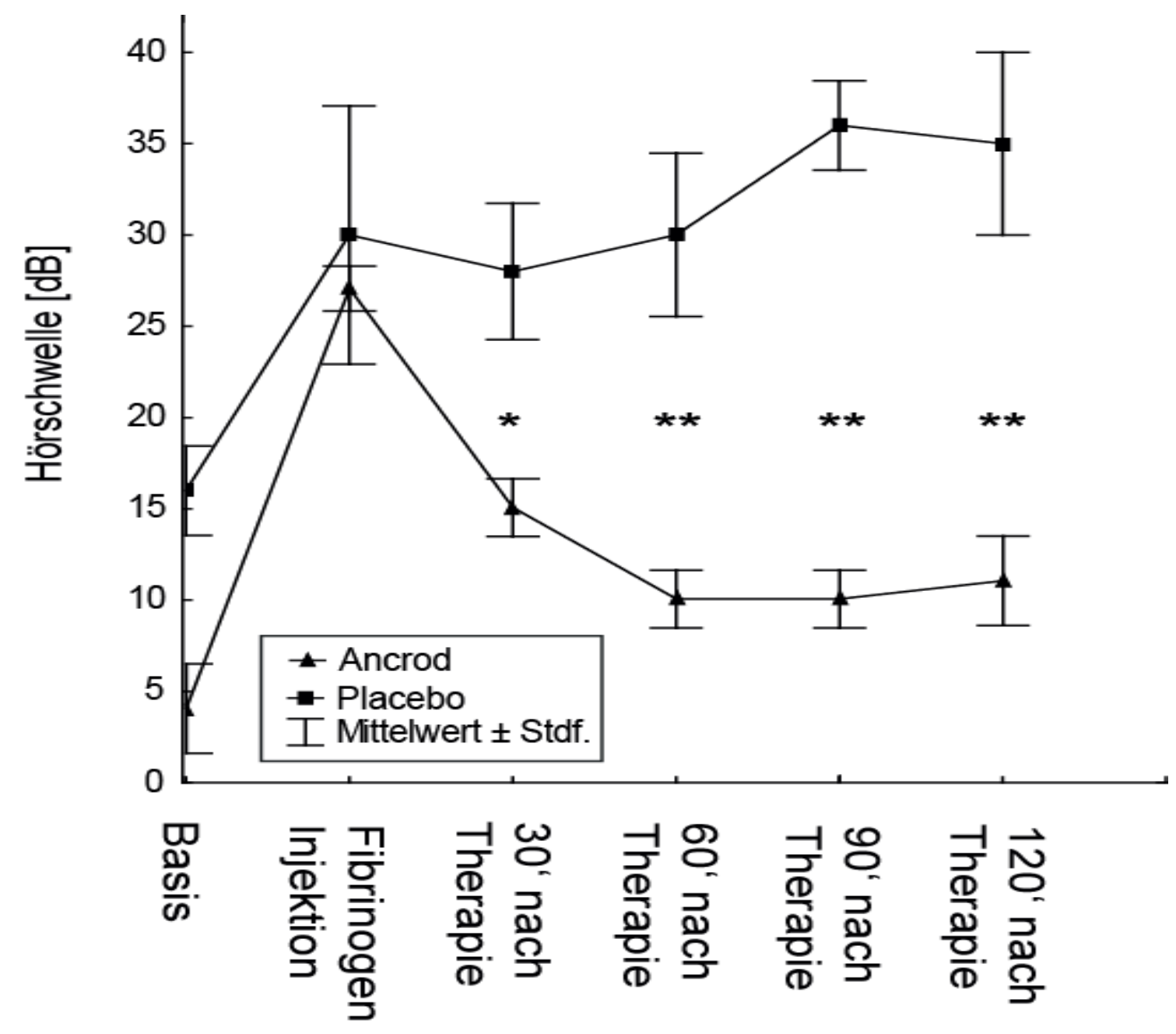

Abbildung 16: Die Ancrod-Gruppe zeigt 30 Minuten nach Therapie eine signifikant geringere Hörschwelle als die Placebo-Gruppe ( $p<0,05)$. Auch 60, 90 und 120 Minuten nach Therapie sind die Werte der Ancrod-Gruppe weiterhin signifikant niedriger als die jeweiligen Messwerte der Placebo-Gruppe $(p<0,01)$. 


\subsubsection{Cochleärer Blutfluss}

Nach Fibrinogen-Injektion und anschließender Therapie mit Placebo oder Ancrod zeigen die beiden Gruppen unterschiedliche Entwicklungen des cochleären Blutflusses. Die PlaceboGruppe verzeichnet eine sinkende Tendenz des cochleären Blutflusses von bis zu $71 \% \pm 1,5$ (Intervall 0,7-0,72) des Basalwertes. Der CBF der Ancrod-Gruppe steigt bis auf $160 \% \pm 72$ (Intervall 1,11-2,87) des Ausgangswertes. Zu den Messzeitpunkten 60-120 Minuten nach Injektion der Prüfsubstanzen wurde ein signifikanter Unterschied im cochleären Blutfluss der Ancrod-Gruppe und der Placebo-Gruppe ermittelt $(t(10)=4,197, p<0,01)$ (Abbildung 17).

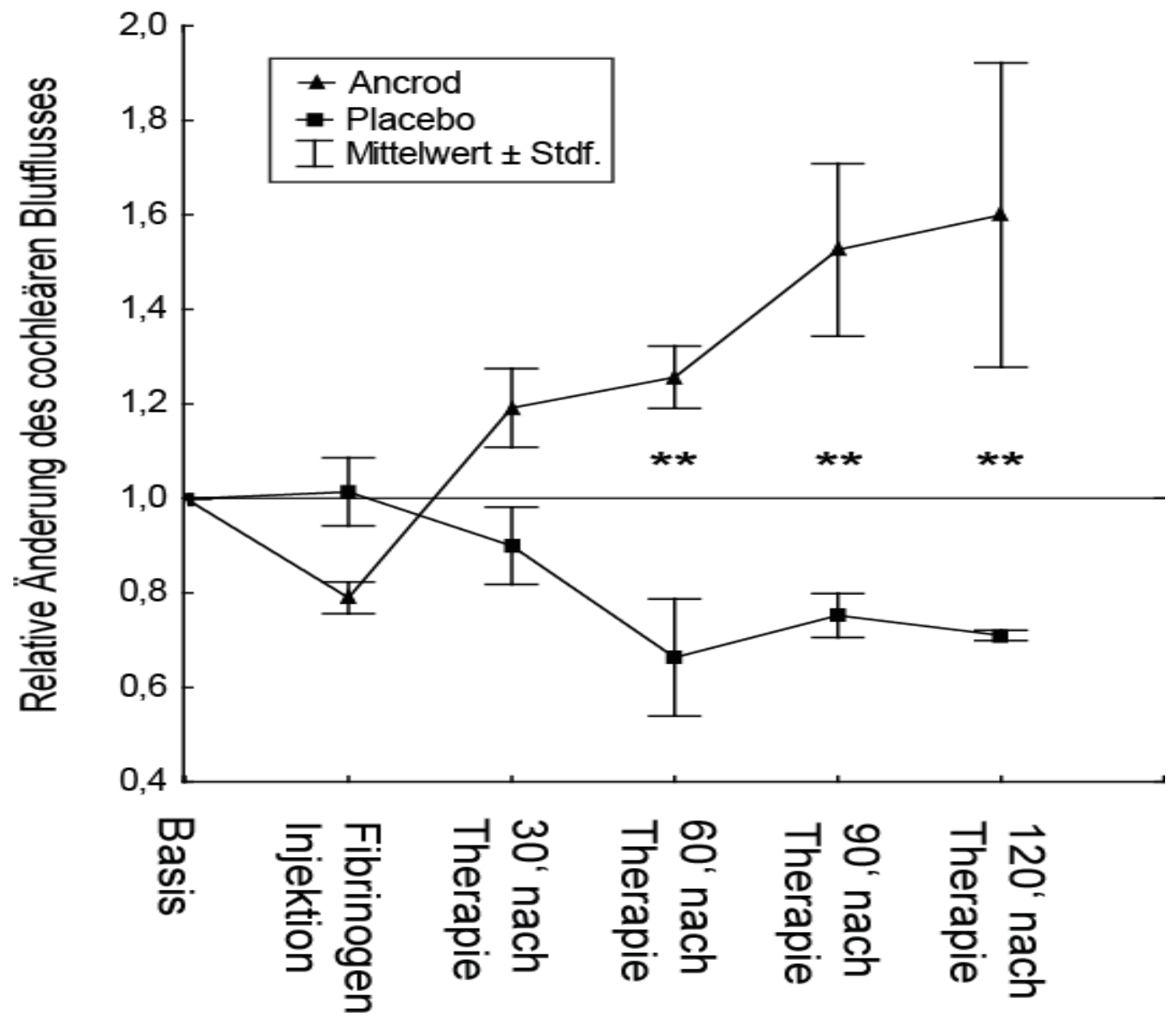

Abbildung 17: Die Ancrod-Gruppe zeigt für die Messzeitpunkte 60, 90 und 120 Minuten nach Therapie jeweils signifikant erhöhte Werte des cochleären Bluflusses gegenüber den enstprechenden Messwerten der PlaceboGruppe $(p<0,01)$. 


\section{Diskussion}

\subsection{Fibrinogen und Hörsturz}

Die vorliegende Arbeit hat Fibrinogen als einen Einflussfaktor auf das Hörvermögen bestätigt. Im Rahmen der Experimente wurde durch eine künstlich herbeigeführte Hyperfibrinogenämie ein akuter Hörverlust induziert. Darüber hinaus zeigte sich ein deutlicher Trend zu einer Reduktion des cochleären Blutflusses. Die hierbei erreichten Plasmafibrinogenkonzentrationen entsprachen denen pathologischer Hyperfibrinogenämien, wie sie bei Patienten beispielsweise im Rahmen chronischer Entzündungen (z. B. chronisch-obstruktiver pulmonaler Dysfunktion und/oder Atherosklerose) vorkommen (Valvi et al. 2012; Lominadze et al. 2010).

Es ist bekannt, dass eine erhöhte Plasmafibrinogenkonzentration zu einer Erhöhung der Plasmaviskosität und der Erythrozytenaggregation führt (Suckfüll et al. 2002). Weiterhin wurde ein Zusammenhang zwischen Blutviskosität und der Hörschwelle zwischen 2 und $4 \mathrm{kHz}$ beschrieben (Gatehouse et al. 1989). Dementsprechend könnte eine drastische Senkung der Plasmafibrinogenkonzentration zur Behandlung des Hörsturzes therapeutisch eingesetzt werden. In klinischen Studien wurde die Reduktion der Plasmafibrinogenkonzentration mittels Fibrinogen/LDL-Apherese bereits geprüft und zeigte im Vergleich zur bisherigen Standardtherapie mit hochdosierten Kortikosteroiden einen überlegenen Therapieerfolg (Suckfüll et al. 2002). Darüber hinaus führte die Apherese nach Versagen konventioneller Therapiestrategien als second-line Therapie sogar zu einem Zeitpunkt, an dem eine Spontanremission nicht mehr zu erwarten war zu einer Besserung des Hörvermögens (Canis et al. 2012). Ebenso wurde im Rahmen von in-vivo-Untersuchungen beschrieben, dass Batroxobin, als snake venom thrombin-like enzyme verwandt mit Ancrod, durch fibrinolytische Eigenschaften in der Lage ist, den cochleären Blutfluss zu steigern (Kawakami et al. 1992). Auf Basis der signifikanten Korrelation zwischen Blutviskosität und der Hörschwelle (Gatehouse et al. 1989) bietet die Senkung der Plasmafibrinogenkonzentration ein therapeutisches Ziel zur Behandlung eines akuten Hörverlusts. Mittels Defibrinogenierung könnte über eine Steigerung des cochleären Blutflusses eine 
konsekutive Verbesserung der Hörminderung herbeigeführt werden. Dieses Behandlungskonzept sollte in der vorliegenden Arbeit geprüft werden.

Es wurde an einem Akutmodell für einen vaskulär bedingten Hörsturz in vivo mittels Injektion von Fibrinogen über eine akute Hyperfibrinogenämie eine signifikante Reduktion des Hörvermögens herbeigeführt. Vorausgegangene Arbeiten der Arbeitsgruppe zeigten bereits unter Anwendung dieses Meerschweinchen-Tiermodells (Canis et al. 2010) den Zusammenhang zwischen akuter Hyperfibrinogenämie, der Reduktion des cochleären Blutflusses und einer Beeinträchtigung des Hörvermögens (Ihler et al. 2012). Dieses Tiermodell für einen vaskulär bedingten Hörsturz bietet die Grundlage für die im Folgenden diskutierte experimentelle Therapiestudie zur Überprüfung der enzymatischen Defibrinogenierung mittels Ancrod als Strategie zur Behandlung des Hörsturzes in vivo.

\subsection{Therapieerfolg medikamentöser Defibrinogenierung}

Im Rahmen der vorliegenden experimentellen Therapiestudie erfolgte nach Induktion eines akuten Hörverlustes placebokontrolliert die Behandlung mittels Ancrod zur enzymatischen Defibrinogenierung. Unter Ancrod-Therapie zeigte sich eine Reversibilität der Hörstörung, wohingegen sich der Hörverlust nach Applikation von Placebo über den gesamten Versuch konstant hielt. In der gewählten Dosierung senkte Ancrod die pathologische Plasmafibrinogenkonzentration auf Werte, die dem physiologischen Bereich entsprechen. Die vorausgegangenen Werte der pathologischen Hyperfibrinogenämie entsprachen jenen wie sie beispielweise im Rahmen chronischer Entzündungsreaktionen zu beobachten sind (Lominadze et al. 2010; Valvi et al. 2012). Nach Ancrod-Behandlung sank die Plasmafibrinogenkonzentration zu keiner Zeit unter den Durchschnittswert von $90 \mathrm{mg} / \mathrm{dl}$. Folglich sind auch prinzipiell denkbare Nebenwirkungen wie Blutungsereignisse unwahrscheinlich. Kawakami et al. beobachteten in einer in vivo Studie unter der Behandlung mit 10 Batroxobin-Units/kg KG einen Abfall der Plasmafibrinogenkonzentration auf bis zu 0 mg/dl (Michiro Kawakami et al. 1992). Dabei kam es zu Nebenwirkungen in Form von Blutungen aus dem Operationssitus (40 \%) oder aus dem Rektum (20 \%). Die erreichten Fibrinogenkonzentrationen von $0 \mathrm{mg} / \mathrm{dl}$ sind als Überdosierung der 
Fibrinolysebehandlung zu bewerten (Michiro Kawakami et al. 1992). Dieser Überdosierung kann bei der therapeutischen Anwendung von defibrinogenierenden Substanzen zur Behandlung des Hörsturzes durch ein Monitoring über die Plasmafibrinogenkonzentration entgegengewirkt werden. Konzentrationsbestimmungen des Fibrinogens im Blutplasma gehören zu den Routineuntersuchungen in der Labordiagnostik. Darüber hinaus wäre im Falle einer Überdosierung die Substitution von Fibrinogenkonzentrat oder frischem Gefrierplasma eine therapeutische Möglichkeit. Auch wäre die Applikation von a2-Makroglobulin, Nitrophenol-P-Guanidin-Benzoat-Hydrochlorid, Agmatin oder Antithrombin III als Antidot denkbar. Diese Substanzen werden in vitro als Inhibitoren von Ancrod beschrieben (Mackessy 2011).

Unter Behandlung mit Ancrod kam es einhergehend mit Senkung der Plasmafibrinogenkonzentration zu einer signifikanten Steigerung des cochleären Blutflusses auf das bis zu 1,6-fache des Ausgangswertes. Dies könnte unter anderem durch die Reduktion der Viskosität des Blutplasmas zu erklären sein. Es ist bekannt, dass das 340 kDa große Plasmaglykoprotein Fibrinogen ein bestimmender Faktor für die Plasmaviskosität ist. Eine erhöhte Plasmafibrinogenkonzentration steigert die Viskosität und infolge dessen entstehen Scherkräfte, die ihrerseits die Endothelzellen und Thrombozyten beeinflussen (Lin et al. 2000; Nesbitt et al. 2009). Die Endothelzellen exprimieren vermehrt Adhäsine und Integrine, von denen einige als Rezeptoren für Fibrinogen fungieren (Yokoyama et al. 1999; Lominadze et al. 1998). Die Erythrozytenaggregation beeinflusst darüber hinaus den Blutfluss. Durch die Aggregation der Erythrozyten wird die Viskosität des Plasmas erhöht, dies führt in kleinen Gefäßen zu Störungen der Mikrozirkulation bis hin zur Stagnation (Chien et al. 1967). Viele kardiovaskuläre Erkrankungen und zerebrovaskuläre Störungen können unter anderem auf vermehrte Erythrozytenaggregation (Hacioglu et al. 2002; Lominadze et al. 1998; Mchedlishvili et al. 1993; Zannad und Stoltz 1992) und erhöhte Plasmaviskosität zurückgeführt werden (Qizilbash 1995; Lowe et al. 1997). Fibrinogen hat größere Auswirkung auf die Erythrozytenaggregation als viele andere Plasmaproteine (Lominadze et al. 1998; Game et al. 1996).

Neben Ancrod und Batroxobin existiert noch eine Vielzahl anderer SVTLE's, die sich in ihren Wirkmechanismen ähneln. Nur wenige von ihnen wurden bisher für medizinische Zwecke in Betracht gezogen. Es gibt Studien, deren Ergebnisse die fibrinolytische Wirkweise in Frage stellen (Hennerici et al. 2006) oder unerwünschte Nebenwirkungen beschreiben (Levy et al. 2009). Ancrod wurde in Europa und Kanada bereits für Indikationen wie beispielsweise die 
periphere arterielle Verschlusskrankheit, tiefe Beinvenenthrombose und als Embolie-Prophylaxe angewendet (Levy et al. 2009; Castro et al. 2004). Mittels Messung der Plasmafibrinogenkonzentration ist eine Behandlung mit Ancrod durch Routine-Labordiagnostik leicht zu überwachen.

Die nach den Voruntersuchungen von Ihler et al. 2012 erwartete Reduktion des cochleären Blutflusses als Folge einer akuten Hyperfibrinogenämie wurde in der vorliegenden Arbeit nur als Trend beobachtet. Dies zeigte sich im Verlauf der Untersuchung in der Gruppe Placebobehandelter Tiere. Zum finalen Messzeitpunkt 120 Minuten nach Beginn der Therapie betrug der cochleäre Blutfluss $71 \%$ des Ausgangswertes. Mit $n=5$ Tieren pro Versuchsgruppe einer Versuchsreihe mit drei Versuchsgruppen (die Methylprednisolon-Gruppe ist Teil der Promotionsarbeit von Herrn Hendrik Desinger) war aufgrund der Korrektur für multiples Testen die Gruppengröße nicht ausreichend groß, um die Reduktion des cochleären Blutflusses signifikant darzustellen. Mit der primären Zielgröße des Hörvermögens wurde der Therapieerfolg hingegen gezeigt.

\subsection{Medikamentöse Defibrinogenierung als Therapiealternative zum therapeuti- schen Standard}

Mit Batroxobin wurde bereits ein SVTLE in der Behandlung des Hörsturzes getestet (Shiraishi et al. 1991; Fang et al. 2018; Kubo et al. 1988). Auch hat Batroxobin im Tierexperiment mittels Defibrinogenierung eine signifikante Steigerung des cochleären Blutflusses zur Folge (Kawakami et al. 1992). Klinisch konnte mittels Defibrinogenierung gegenüber der Behandlung mit Steroiden eine signifikante Verbesserung des Hörvermögens beobachtet werden (Shiraishi et al. 1991; Kawakami et al. 1992). Während die durchschnittliche Hörschwelle der SteroidGruppe innerhalb einer Woche von $82,3 \mathrm{~dB}$ auf 55,8 dB sank $(n=86)$, konnte eine Entwicklung der Hörschwelle der Defibrinogenierungs-Gruppe von 79,2 dB auf 47,0 dB beobachtet werden (Shiraishi et al. 1991). Weitere Arbeitsgruppen verglichen Steroid-Therapie mit Defibrinogenierungstherapie in der Behandlung des plötzlichen Hörverlustes. Kubo et al. zeigten einen höheren Anteil an Restitution des Hörvermögens in der defibrinogenierten Patientengruppe 
als in dem mit Steroiden behandelten Patientenkollektiv (Kubo et al. 1988). Bei Suzuki et al. zeigte sich in Bezug auf die Verbesserung des Hörvermögens kein Unterschied zwischen der Patientengruppe nach Defibrinogenisierung und der mit Steroiden behandelten Patientengruppe (Suzuki et al. 2003). Diese Ergebnisse zeigen, dass die Fibrinogenolytika eine mögliche Alternative in der Behandlung des Hörsturzes darstellen könnten. Die Vielzahl der plötzlich aufgetretenen Hörverluste wird bei unbekannter Ursache als idiopathisch gewertet. Die Hyperfibrinogenämie als bekannter Risikofaktor für die Entstehung eines Hörsturzes kann durch Routinediagnostik aus Citratplasma diagnostisch leicht bestätigt oder ausgeschlossen werden, sodass Patienten mit Hörsturz und erhöhter Plasmafibrinogenkonzentration gut zu identifizieren sind und dementsprechend zielgerichtet behandelt werden könnten. Unabhängig davon wird die cochleäre Mikrozirkulation als gemeinsame Endstrecke auch anderer pathogenetischer Faktoren in der Entstehung eines Hörsturzes diskutiert (Arpornchayanon et al. 2013; Cuna et al. 2015; García Callejo et al. 1997; Lazarini and Camargo 2006; Axelsson 1968), sodass die medikamentöse Defibrinogenierung auch als generelle Behandlungsstrategie eines plötzlichen idiopathischen sensorineuralen Hörverlustes in Erwägung gezogen werden könnte. Die Ergebnisse der vorliegenden Arbeit stützen diese Behandlungsstrategie.

Die klinische Bedeutung der vorliegenden Arbeit liegt zudem in der noch immer insuffizienten Möglichkeit, den Hörsturz zu therapieren. Der aktuelle therapeutische Standard ist die hochdosierte Therapie mit Kortikosteroiden, jedoch wurde die Wirksamkeit dieser Behandlungsstrategie auch in Metaanalysen nicht zufriedenstellend belegt (Wei et al. 2013; Crane et al. 2015). Auch klinische Studien zur medikamentösen Defibrinogenierung in der Behandlung des Hörsturzes stützen diese Ergebnisse. Die Behandlung mit oral verabreichten Kortikosteroiden zeigt weder im Vergleich zu Placebo noch zur Defibrinogenierung mit Batroxobin signifikant bessere Ergebnisse in der Behandlung des Hörsturzes (Conlin und Parnes 2007; Kubo et al. 1988). Die medikamentöse Defibrinogenierung mit Batroxobin hingegen konnte im Vergleich zur Behandlung mit dem Betamethason besonders im Bereich von tiefen und mittleren Frequenzen eine signifikante Verbesserung der Hörschwelle aufweisen (Shiraishi et al. 1991). 


\subsection{Stärken und Limitationen der Methodik}

In der vorgestellten Versuchsreihe wurde im Kontext einer pathologischen Hyperfibrinogenämie nach medikamentöser Defibrinogenierung mit Ancrod eine Steigerung des cochleären Blutflusses beobachtet. Kawakami et al. haben einen erhöhten cochleären Blutfluss nach enzymatischer Defibrinogenierung bei physiologischer Plasmafibrinogenkonzentration darstellen können (Kawakami et al. 1992). Kawakami et al. bestimmten den Blutfluss mittels LaserDoppler-Anemometrie. Diese Methode misst jedoch nicht spezifisch den kapillaren Blutfluss der Stria vascularis. Durch die Nutzung der Intravitalmikroskopie hat die vorliegende Untersuchung die Ergebnisse von Kawakami et al. spezifisch für den cochleären Blutfluss im Bereich der Stria vascularis bestätigt. Zudem hat das vorliegend diskutierte Experiment gleichzeitig sowohl Auswirkungen der Hyperfibrinogenämie auf die Hörschwelle als auch die Auswirkungen des therapeutischen Ansatzes der medikamentösen Defibrinogenierung mittels Ancrod placebokontrolliert dargestellt.

Bei dem Versuchsaufbau handelt es sich um einen Akutversuch, der operative Zugang sowie die lange Narkosezeit limitieren die Untersuchung zeitlich. Mit einem abgewandelten Versuchsaufbau für einen fibrinogeninduzierten Hörverlust könnte die Wirksamkeit von Ancrod auch in ihrer zeitlichen Charakteristik in Bezug auf den Therapiebeginn untersucht werden. Hierbei kann der cochleäre Blutfluss jedoch nicht in beschriebener Weise mittels Intravitalmikroskopie untersucht werden, da der operative Zugang eine zeitliche Begrenzung des Versuchsablaufs bedingt. Der Versuchsaufbau mit langer Narkosezeit und operativ exponierter Stria vascularis eignet sich nicht für Messungen des cochleären Blutflusses über einen längeren Zeitraum. Dies zeigt sich unter anderem an den mit Dauer des Experiments zunehmenden Schwankungen des arteriellen Mitteldrucks. Ebenfalls kam es während längerer Exposition der Stria vascularis zu einer Koagulation einzelner Gefäße, was eine Messung des cochleären Blutflusses erschwerte. Darüber hinaus sind rezidivierende Blutentnahmen von etwa $500 \mu$ l bei einem Gesamtblutvolumen von 69-75 ml/kg KG nur in eingeschränktem Maße möglich. Eine Alternative zur Intravitalmikroskopie könnte hier die Laser-Doppler-Methode darstellen, nicht nur für In-vivo-Experimente an Meerschweinchen, sondern auch in klinischen Versuchen (Levine et al. 1993). Da hierbei jedoch nicht selektiv Gefäße der Stria vascularis untersucht werden, bleibt auch hier die Aussagekraft eingeschränkt. 
In der vorliegenden Arbeit nicht untersucht wurden die Auswirkungen unterschiedlicher Zeitpunkte eines Therapiebeginns, ob Ancrod in Kombination mit anderen Therapeutika einen anderen oder besseren Therapieeffekt aufweist oder wie sich die Langzeitergebnisse darstellen.

\subsection{Schlussfolgerung}

Zusammenfassend wurde in der vorliegenden Arbeit gezeigt, wie Ancrod bei dem durch akute Hyperfibrinogenämie induzierten akuten vaskulär bedingten Hörverlust mittels Senkung der Plasmafibrinogenkonzentration auf physiologische Werte eine Reversibilität der Hörminderung herbeigeführt hat und mit einer deutlichen Steigerung des cochleären Blutflusses einherging. Die Placebobehandlung hatte keine Auswirkungen auf diese Parameter. Die Ergebnisse stützen die Therapiestrategie einer Senkung der Plasmafibrinogenkonzentration zur Behandlung des Hörsturzes.

\section{Zusammenfassung}

\subsection{Deutsch}

Der Hörsturz ist eine der häufigsten Erkrankungen des Innenohrs, deren Ätiologie in den meisten Fällen ungeklärt bleibt. Einer der diskutierten Gründe ist die Mikrozirkulationsstörung, die primäre Ursache, aber auch eine gemeinsame Endstrecke anderer ätiopathogenetischer Faktoren darstellen kann. Fibrinogen ist ein Einflussfaktor auf die Mikrozirkulation, und eine Hyperfibrinogenämie wurde unlängst als ein Risikofaktor für die Entstehung eines Hörsturzes identifiziert. Die vorliegende Arbeit demonstrierte an einem Tiermodell die negative Auswirkung der akuten Hyperfibrinogenämie auf das Hörvermögen. Dieses Tiermodell ermöglicht die simultane Messung des Hörvermögens mittels Hirnstammaudiometrie und der cochleären 
Mikrozirkulation mittels Intravitalmikroskopie. Zudem sind über einen zentralen Venenzugang Blutentnahmen wie auch die Applikation von Substanzen und Wirkstoffen möglich. Mittels akuter Hyperfibrinogenämie wurde eine Hörminderung induziert. In einem zweiten Schritt wurde im Rahmen einer experimentellen Therapiestudie die Möglichkeit der medikamentösen Defibrinogenierung mit Ancrod zur Behandlung des vaskulär bedingten Hörverlusts demonstriert. Die Senkung der pathologischen Plasmafibrinogenkonzentration auf physiologische Werte durch Applikation von Ancrod hatte eine Reversibilität der Hörminderung zur Folge, zudem zeigte sich eine deutliche Steigerung des cochleären Blutflusses. Eine PlaceboTherapie hatte weder Auswirkungen auf das Hörvermögen noch auf die Parameter der cochleären Mikrozirkulation.

Ancrod wurde in Europa und Kanada bereits für Indikationen, wie beispielsweise die periphere arterielle Verschlusskrankheit, tiefe Beinvenenthrombose und als Embolie-Prophylaxe vermarktet. Mittels Messung der Plasmafibrinogenkonzentration ist die Behandlung mit Ancrod durch gängige Labordiagnostik leicht zu überwachen. Die Senkung der Plasmafibrinogenkonzentration könnte bei plötzlichem Hörverlust als Therapiestrategie in Erwägung gezogen werden.

\subsection{Englisch}

Sudden hearing loss is one of the most common inner-ear diseases. The underlying pathomechanism is still not fully understood and most often it remains idiopathic. One of its discussed causes is the disturbance of cochlear microcirculation that is either the primary cause but also considered to be the final common pathway of other aetiopathological factors. Fibrinogen affects microcirculation and hyperfibrinogenemia was identified as a risk factor for sudden hearing loss. The present study demonstrated in vivo that acute hyperfibrinogenemia increases hearing threshold. The animal model allows simultaneous measurement of hearing threshold by brainstem evoked response audiometry, and cochlear blood flow by intravital microscopy. Furthermore, by a central venous catheter, blood samples can be taken, and application of medication is possible. A sudden hearing loss was induced by acute hyperfibrinogenemia. Next, in an experimental therapy trial, drug-induced defibrinogenation by ancrod 
was demonstrated for treatment of this vascular inner ear impairment. Reduction of pathologic fibrinogen levels was followed by an increase of cochlear blood flow, accompanied by a recovery of hearing loss. Placebo treatment had no effect on hearing thresholds or parameters of cochlear microcirculation. Ancrod was already marketed in Europe and Canada for indications like peripheral arterial occlusive disease, deep vein thrombosis, and prophylaxis for thromboembolism. It is safe and easy to monitor by routine laboratory tests measuring plasma fibrinogen level. The reduction of plasma fibrinogen might serve as a future treatment option for acute hearing loss. 


\section{Literaturverzeichnis}

Acharya SS, DiMichele DM (2008): Rare inherited disorders of fibrinogen. Haemophilia 14 , 11511158

Arpornchayanon W, Canis M, Ihler F, Settevendemie C, Strieth S (2013): TNF- $\alpha$ inhibition using etanercept prevents noise-induced hearing loss by improvement of cochlear blood flow in vivo. Int J Audiol $\underline{52}, 545-552$

Au LC, Lin SB, Chou JS, Teh GW, Chang KJ, Shih CM (1993): Molecular cloning and sequence analysis of the cDNA for ancrod, a thrombin-like enzyme from the venom of Calloselasma rhodostoma. Biochem J 294 (Pt 2), 387-390

Axelsson A (1968): The vascular anatomy of the cochlea in the guinea pig and in man. Acta Otolaryngol, Suppl 243-246

Baker M, Wayland H (1974): On-line volume flow rate and velocity profile measurement for blood in microvessels. Microvasc Res $\underline{7}, 131-143$

Berg HM, Cohen NL, Hammerschlag PE, Waltzman SB (1986): Acoustic neuroma presenting as sudden hearing loss with recovery. Otolaryngol Head Neck Surg $\underline{94}$, 15-22

Blombäck B, Blombäck M, Edman P, Hessel B (1966): Human fibrinopeptides isolation, characterization and structure. Biochim Biophys Acta Gen Subj 115, 371-396

Byl FM (1984): Sudden hearing loss: eight years' experience and suggested prognostic table. Laryngoscope $94,647-661$

Canis M, Arpornchayanon W, Messmer C, Suckfuell M, Olzowy B, Strieth S (2010): An animal model for the analysis of cochlear blood flow [corrected] disturbance and hearing threshold in vivo. Eur Arch Otorhinolaryngol 267, 197-203

Canis M, Heigl F, Suckfuell M (2012): Fibrinogen/LDL apheresis is a promising rescue therapy for sudden sensorineural hearing loss. Clin Res Cardiol Suppl $\underline{7}, 36-40$

Castro HC, Zingali RB, Albuquerque MG, Pujol-Luz M, Rodrigues CR (2004): Snake venom thrombinlike enzymes: From reptilase to now. Cell Mol Life Sci $\underline{61}, 843-856$

Chau JK, Lin JRJ, Atashband S, Irvine RA, Westerberg BD (2010): Systematic review of the evidence for the etiology of adult sudden sensorineural hearing loss. Laryngoscope $120,1011-1021$

Chien S, Usami S, Dellenback RJ, Gregersen MI, Nanninga LB, Guest MM (1967): Blood viscosity: influence of erythrocyte aggregation. Science $\underline{157}, 829-831$

Clauss A (1957): Gerinnungsphysiologische Schnellmethode zur Bestimmung des Fibrinogens. Acta Haematol $17,237-246$ 
Conlin AE, Parnes LS (2007): Treatment of Sudden Sensorineural Hearing Loss. Arch Otolaryngol Head Neck Surg $\underline{133}, 582$

Crane RA, Camilon M, Nguyen S, Meyer TA (2015): Steroids for treatment of sudden sensorineural hearing loss: A meta-analysis of randomized controlled trials. Laryngoscope $125,209-217$

Cuna V, Battaglino G, Capelli I, Sala E, Donati G, Cianciolo G, La Manna G (2015): Hypoacusia and chronic renal dysfunction: New etiopathogenetic prospective. Ther Apher Dial $\underline{19}, 111-118$

Dempfle C-E, Argiriou S, Alesci S, Kucher K, Müller-Peltzer H, Rübsamen K, Heene DL (2001): Fibrin Formation and Proteolysis during Ancrod Treatment. Ann N Y Acad Sci 936, 210-214

Ewart MR, Hatton MW, Basford JM, Dodgson KS (1970): The proteolytic action of Arvin on human fibrinogen. Biochem J 118, 603-609

Fang X, Yu LS, Ma X, Xia RM, Jiang YH, Liu HX, Jing YY (2018): Correlation between the changes of fibrinogen and the treatment effect of all-frequency sudden deafness. World J Otorhinolaryngol Head Neck Surg $\underline{53}$ 3-8

Foden N, Mehta N, Joseph T (2013): Sudden onset hearing loss--causes, investigations and management. Aust Fam Physician 42, 641-644

Game L, Voegel JC, Schaaf P, Stoltz JF (1996): Do physiological concentrations of IgG induce a direct aggregation of red blood cells: comparison with fibrinogen. Biochim Biophys Acta $\underline{1291}, 138$ 142

García Callejo FJ, Velert Vila MM, Orts Alborch MH, Pardo Mateu L, Monzó Gandía R, Marco Algarra J (1997): Trastornos en la viscosidad sanguínea como factor etiopatogénico en la sordera brusca. Acta Otorrinolaringol Esp $\underline{48}, 517-522$

Gatehouse S, Gallacher JEJ, Lowe GDO, Yarnell JWG, Hutton RD, Ising I (1989): Blood Viscosity and Hearing Levels in the Caerphilly Collaborative Heart Disease Study. Arch Otolaryngol Head Neck Surg $\underline{115}, 1227-1230$

Gussen R (1976): Sudden deafnfess of vascular origin: a human temporal bone study. Ann Otol Rhinol Laryngol $\underline{85}, 94-100$

Hacioglu G, Yalcin O, Bor-Kucukatay M, Ozkaya G, Baskurt OK (2002): Red blood cell rheological properties in various rat hypertension models. Clin Hemorheol Microcirc 26, 27-32

Hennerici MG, Kay R, Bogousslavsky J, Lenzi GL, Verstraete M, Orgogozo JM (2006): Intravenous ancrod for acute ischaemic stroke in the European Stroke Treatment with Ancrod Trial: a randomised controlled trial. Lancet $\underline{368}, 1871-1878$

Ihler F, Strieth S, Pieri N, Göhring P, Canis M (2012): Acute hyperfibrinogenemia impairs cochlear blood flow and hearing function in guinea pigs in vivo. Int J Audiol 51, 210-215

Jeans AR, Wilkins EGL, Bonington A (2008): Sensorineural hearing loss due to secondary syphilis. Int J STD AIDS $\underline{19}, 355-356$ 
Jensen T, Kierulf P, Sandset PM, Klingenberg O, Joø GB, Godal HC, Skjønsberg OH (2007): Fibrinogen and fibrin induce synthesis of proinflammatory cytokines from isolated peripheral blood mononuclear cells. Thromb Haemost 97 , 822-829

Jewett DL, Williston JS (1971): Auditory-evoked far fields averaged from the scalp of humans. Brain 94, 681-696

Kawakami M, Makimoto K, Yamamoto H, Takahashi H (1992): The effect of batroxobin on cochlear blood flow. Acta Otolaryngol $\underline{112,}$ 991-997

Kubo T, Matsunaga T, Asai H, Kawamoto K, Kusakari J, Nomura Y, Oda M, Yanagita N, Niwa H, Uemura T et al. (1988): Efficacy of Defibrinogenation and Steroid Therapies on Sudden Deafness. Arch Otolaryngol Head Neck Surg 114, 649-652

Kuhn M, Heman-Ackah SE, Shaikh JA, Roehm PC (2011): Sudden sensorineural hearing loss: a review of diagnosis, treatment, and prognosis. Trends Amplif $\underline{15}, 91-105$

Lazarini PR, Camargo ACK (2006): Idiopathic sudden sensorineural hearing loss: Etiopathogenic aspects. Braz J Otorhinolaryngol $\underline{72}, 554-561$

Levine RA, Bu-Saba N, Brown MC (1993): Laser-Doppler measurements and electrocochleography during ischemia of the guinea pig cochlea: implications for hearing preservation in acoustic neuroma surgery. Ann Otol Rhinol Laryngol 102, 127-136

Levy DE, del Zoppo GJ, Demaerschalk BM, Demchuk AM, Diener H-C, Howard G, Kaste M, Pancioli AM, Ringelstein EB, Spatareanu C et al. (2009): Ancrod in Acute Ischemic Stroke: Results of 500 Subjects Beginning Treatment Within 6 Hours of Stroke Onset in the Ancrod Stroke Program. Stroke $\underline{40}, 3796-3803$

Lin K, Hsu P-P, Chen BP, Yuan S, Usami S, Shyy JY-J, Li Y-S, Chien S (2000): Molecular mechanism of endothelial growth arrest by laminar shear stress. Proc Natl Acad Sci USA 97, 9385-9389

Lominadze D, Joshua IG, Schuschke DA (1998): Increased erythrocyte aggregation in spontaneously hypertensive rats. Am J Hypertens $\underline{11}, 784-789$

Lominadze D, Dean WL, Tyagi SC, Roberts AM (2010): Mechanisms of fibrinogen-induced microvascular dysfunction during cardiovascular disease. Acta Physiol (Oxf) 198, 1-13

Lowe GD, Lee AJ, Rumley A, Price JF, Fowkes FG (1997): Blood viscosity and risk of cardiovascular events: the Edinburgh Artery Study. Br J Haematol $\underline{96}, 168-173$

Mackessy SP: Thrombin-Like Enzymes in Snake Venoms; In: Kini MR, Clemetson KJ, Markland FS, McLane MA, Morita T (Hrsg.): Toxins and Hemostasis. Springer Netherlands, Dordrecht 2011, 519-557

Mannini L, Paniccia R, Cecchi E, Alessandrello Liotta A, Leprini E, Berloco P, Pagnini P, Abbate R, Franco Gensini G, Prisco D (2005): Reduced erythrocyte deformability and hypercoagulability in idiopathic sudden sensorineural hearing loss. Clin Hemorheol Microcirc $\underline{33}, 47-55$

Mattox DE, Simmons FB (1977): Natural history of sudden sensorineural hearing loss. Ann Otol Rhinol Laryngol $\underline{86}, 463-480$ 
Mchedlishvili G, Beritashvili N, Lominadze D, Tsinamdzvrishvili B (1993): Technique for direct and quantitative evaluation of erythrocyte aggregability in blood samples. Biorheology $\underline{30}, 153-$ 161

Nakashima T, Naganawa S, Sone M, Tominaga M, Hayashi H, Yamamoto H, Liu X, Nuttall AL (2003): Disorders of cochlear blood flow. Brain Res Rev $\underline{43}, 17-28$

Nesbitt WS, Westein E, Tovar-Lopez FJ, Tolouei E, Mitchell A, Fu J, Carberry J, Fouras A, Jackson SP (2009): A shear gradient-dependent platelet aggregation mechanism drives thrombus formation. Nat Med $\underline{15}, 665-673$

Olzowy B, Osterkorn D, Suckfüll M (2005): Praktische Erfahrung bestätigt. Hörsturz wesentlich häufiger als bisher angenommen. MMW Fortschr Med 147, 37-38

Prentice CR, Hampton KK, Grant PJ, Nelson SR, Nieuwenhuizen W, Gaffney PJ (1993): The fibrinolytic response to ancrod therapy: characterization of fibrinogen and fibrin degradation products. $\mathrm{Br} J$ Haematol $\underline{83}, 276-281$

Qizilbash N (1995): Fibrinogen and cerebrovascular disease. Eur Heart J Suppl 16, 42-45; discussion 45-46

Scherer EQ, Yang J, Canis M, Reimann K, Ivanov K, Diehl CD, Backx PH, Wier WG, Strieth S, Wangemann $P$ et al. (2010): Tumor necrosis factor- $\alpha$ enhances microvascular tone and reduces blood flow in the cochlea via enhanced sphingosine-1-phosphate signaling. Stroke $\underline{41}, 2618$ 2624

Sharaf K, Ihler F, Bertlich M, Reichel CA, Berghaus A, Canis M (2016): Tumor Necrosis Factor-induced Decrease of Cochlear Blood Flow Can Be Reversed by Etanercept or JTE-013. Otol Neurotol 37, 203-208

Sherman DG (2002): Ancrod. Curr Med Res Opin 18 Suppl 2, 52

Shiraishi T, Kubo T, Matsunaga T (1991): Chronological study of recovery of sudden deafness treated with defibrinogenation and steroid therapies. Acta Otolaryngol 111, 867-871

Suckfüll M, Wimmer C, Reichel O, Mees K, Schorn K (2002): Hyperfibrinogenemia as a risk factor for sudden hearing loss. Otol Neurotol $\underline{23}, 309-311$

Suzuki H, Furukawa M, Kumagai M, Takahashi E, Matsuura K, Katori Y, Shimomura A, Kobayashi T (2003): Defibrinogenation therapy for idiopathic sudden sensorineural hearing loss in comparison with high-dose steroid therapy. Acta Otolaryngol $\underline{123}$, 46-50

Valvi D, Mannino DM, Müllerova H, Tal-Singer R (2012): Fibrinogen, chronic obstructive pulmonary disease (COPD) and outcomes in two United States cohorts. Int J Chron Obstruct Pulmon Dis 7, 173-182

Vuori M, Lahikainen EA, Peltonen T (1962): Perceptive deafness in connection with mumps. A study of 298 servicemen suffering from mumps. Acta Otolaryngol $\underline{55}, 231-236$

Weber PC, Deschler DG, Lin FH (2013): sudden sensorineural hearing loss. http://www.uptodate.com 
Wei BPC, Stathopoulos D, O'Leary S (2013): Steroids for idiopathic sudden sensorineural hearing loss. Cochrane Database Syst Rev , CD003998

Yokoyama K, Zhang XP, Medved L, Takada Y (1999): Specific binding of integrin alpha $v$ beta 3 to the fibrinogen gamma and alpha $\mathrm{E}$ chain C-terminal domains. Biochemistry $\underline{38}, 5872-5877$

Zannad F, Stoltz JF (1992): Blood rheology in arterial hypertension. Journal of hypertension. J Hypertens Suppl $\underline{10}, 78$

Zeintl H, Sack FU, Intaglietta M, Messmer K (1989): Computer assisted leukocyte adhesion measurement in intravital microscopy. Int J Microcirc Clin Exp $\underline{8}$, 293-302 
Teile dieser Doktorarbeit wurden auf Konferenzen in Form von Postern, Vorträgen und Abstracts vorgestellt.

\section{Originalarbeiten:}

Weiss BG, Bertlich M, Bettag SA, Desinger H, Ihler F, Canis M (2017): Drug-induced defibrinogenation as new treatment approach of acute hearing loss in an animal model for inner ear vascular impairment. Otol Neurotol 38(5):648-654.

\section{Patentanmeldung}

Weiss BG, Canis M. Neue Verwendung von Ancrod bei Innenohrerkrankungen. Patentanmeldung beim Deutschen Patent- und Markenamt am 12.05.2015, Anmeldenummer DE 102015107469.9

\section{Poster / Präsentationen / Abstracts:}

Weiss BG, Bertlich M, Bettag SA, Desinger H, Ihler F, Canis M. Medikamentöse Defibrinogenierung als neuer Therapieansatz des akuten Hörverlusts in einem vaskulären Schädigungsmodell des Innenohres in vivo. Herbsttagung der Arbeitsgemeinschaft Deutschsprachiger Audiologen, Neurootologen und Otologen (ADANO), Bern 2015

Weiss BG, Bertlich M, Bettag SA, Canis M, Desinger H, Ihler F. Medikamentöse Defibrinogenierung zur Therapie des akuten Hörverlusts in einem vaskulären Schädigungsmodell des Innenohres in vivo. DGHNO, Berlin 2015 


\section{Danksagung}

Mein besonderer Dank gilt meinem Doktorvater Prof. Dr. Martin Canis für die freundliche Vergabe des Themas und die hervorragende Betreuung der Arbeit.

Ebenfalls möchte ich mich bei meinem Betreuer Dr. Bernhard Weiss bedanken. Seine Ideen, Kommentare und Korrekturen waren für mich immer hilfreich, er stand mir stets mit Rat und Tat zur Seite.

Dr. Mattis Bertlich danke ich sehr für die Einarbeitung in die Mikrochirurgie. Er unterstützte mich auch bezüglich des Umgangs mit allen technischen Geräten und half stets bei Problemen und organisatorischen Herausforderungen.

Weiterhin danke ich Frau Jutta Engelmayer aus dem Institut für klinische Chemie der Universitätsmedizin Göttingen für ihre Hilfe und Beratung. 


\section{Lebenslauf}

Am 30.01.1990 wurde ich in Essen als zweites Kind meiner Eltern Christa Bettag, geb. Kiwit, und Prof. Dr. Martin Bettag geboren.

Von 1996 bis 2000 besuchte ich die Schloss-Ardeck-Grundschule in Gau-Algesheim, ab 2000 das Friedrich-Wilhelm-Gymnasium Trier, an welchem ich im März 2009 meine Schulausbildung mit dem Abitur beendete.

Von 2009 bis 2010 absolvierte ich als Rettungssanitäter ein Freiwilliges Soziales Jahr bei der Lehrrettungswache der Berufsfeuerwehr Trier.

Zum Sommersemester 2010 begann ich das Studium der Zahnheilkunde an der Georg-August-Universität Göttingen und beendete es im November 2015 mit dem Abschluss der Zahnärztlichen Prüfung. Meine Approbation als Zahnarzt erhielt ich am 14.12.2015. Bereits während des Studiums begann ich mit den experimentellen Arbeiten zu meiner vorliegenden Dissertation mit dem Thema „Medikamentöse Defibrinogenierung zur Behandlung des akuten Hörverlustes - eine verblindete, Placebo-kontrollierte in vivo-Studie“ in der Arbeitsgruppe von Herrn Prof. Dr. med. Martin Canis.

Im Sommersemester 2016 begann ich das Studium der Humanmedizin an der Georg-AugustUniversität Göttingen und ich studiere momentan im 8. Fachsemester. 